\title{
Optimal Manufacturing-Remanufacturing Production Policy for a Closed-Loop Supply Chain under Fill Rate and Budget Constraint in Bifuzzy Environments
}

\author{
Soumita Kundu, ${ }^{1}$ Tripti Chakrabarti, ${ }^{1}$ and Dipak Kumar Jana ${ }^{2}$ \\ ${ }^{1}$ Department of Applied Mathematics, University of Calcutta, 92 APC Road, Kolkata, West Bengal 700009, India \\ ${ }^{2}$ Department of Applied Science, Haldia Institute of Technology, Purba Midnapur, West Bengal 721657, India \\ Correspondence should be addressed to Dipak Kumar Jana; dipakjana@gmail.com
}

Received 31 December 2013; Accepted 12 May 2014; Published 24 June 2014

Academic Editor: Tamer Eren

Copyright (c) 2014 Soumita Kundu et al. This is an open access article distributed under the Creative Commons Attribution License, which permits unrestricted use, distribution, and reproduction in any medium, provided the original work is properly cited.

\begin{abstract}
We study a closed-loop supply chain involving a manufacturing facility and a remanufacturing facility. The manufacturer satisfies stochastic market demand by remanufacturing the used product into "as-new" one and producing new products from raw material in the remanufacturing facility and the manufacturing facility, respectively. The remanufacturing cost depends on the quality of used product. The problem is maximizing the manufacturer's expected profit by jointly determining the collected quantity of used product and the ordered quantity of raw material. Following that we analyze the model with a fill rate constraint and a budget constraint separately and then with both the constraints. Next, to handle the imprecise nature of some parameters of the model, we develop the model with both constraints in bifuzzy environment. Finally numerical examples are presented to illustrate the models. The sensitivity analysis is also conducted to generate managerial insight.
\end{abstract}

\section{Introduction}

In recent years more and more attention has been paid to recycling and remanufacturing of used products due to the increased environmental concerns, reduced waste, and awareness of natural resources limitation worldwide. Remanufacturing the used product and then sending them back to market "as-new" product are considered a part of closed-loop supply chain (CLSC), along with operations like acquisition/collection, testing, repairing, manufacturing, and distribution. Many product categories, from car batteries to printer cartridge and computers, can be made new in this way.

With the integration of a remanufacturing facility in a manufacturing system the complexity is increasing and therefore also the production planning is getting more challenging to the manufacturer. van der Laan et al [1] and Krikke [2] study the production planning and inventory control problem for a closed-loop system where manufacturing and remanufacturing operations occur simultaneously. All the products produced by the manufacturing process and the remanufacturing process can be used to fulfil customer demands. Two control strategies are analyzed: the PUSH strategy where all returned products are remanufactured as early as possible; the PULL strategy where all returned products are remanufactured as late as it is convenient. Inderfurth [3] analyzes the optimal policies to control a hybrid manufacturing-remanufacturing system, in which the two operations are not directly interconnected if remanufactured items are downgraded and have to be sold in markets different from those for new products. But in case of a shortage of remanufactured products, brand-new products can be used to substitute the remanufactured ones. Dobos and Richter [4] discussed a similar system in which the disposal option of the returned items is allowed and all the recycling batches follow the production batches. Choi et al. [5] present a joint EOQ and EPQ model for an inventory control problem in a closed-loop system, in which a stationary demand is satisfied by recovered products and newly purchased products. Rubio and Corominas [6] investigate a reverse logistics system when it is operated in a lean production environment. They 
analyze the coordination of capacity between manufacturing and remanufacturing and develop the optimal production policies of the system.

One of the core management issues in remanufacturing industry is to effectively match demand and supply by dealing with the uncertainty of the quality of the returned products and of the market demand, since the returned products are not presorted in many cases and the information about their quality is usually limited to firms. The "yield rate", which is the remanufacturable portion of the used item is random. Some comprehensive reviews of the problem can be found in Yano and Lee's work [7]. Hsu and Bassok [8] obtain the optimum production quantity by solving a single-period, multiproduct, downward substitution model with random yields and demand. Bollapragada and Morton [9] present heuristics for the random yield problem of periodically reviewed inventory. Kazaz [10] studies production planning with random yield and demand with a particular focus on olive oil production.

Competitive pressure in today's global market is forcing companies to offer superior service to customers. Customer satisfaction or the ability to effectively respond to customer demand can be gauged by measuring service level (Steven [11]). Service level is defined in many ways; the simplest definition is the fraction of orders that are filled on or before their delivery due date (Steven [11]). There are two types of service level measures. The first one is type 1 service level which measures the probability of no stock-out over a planning period. The second one is fill rate which measures the fraction of demand that is satisfied immediately from onhand inventory. Zipkin [12] considered a single-stage model with a compound Poisson demand process. He obtained exact and approximate fill rate expressions and presented methods for minimizing inventory cost subject to a fill rate constraint. Axsäter [13] considered the problem of finding an optimal $(R, Q)$ policy under a fill rate constraint and normally distributed lead-time demand and he concluded that the savings are large for low service levels but small for high service levels.

All the research works discussed above considered parameters of inventory model as constant or as function of time or as random variable with known probability distribution that is crisp in nature. But in real life, the most part of the information about inventory parameters are available in imperfect form. So it becomes impossible to make precise statement about the different inventory parameters. Fuzzy set theory by Zadeh [14] is very appropriate tool for handling these situations. Based on these theories, if the inventory parameters are treated as fuzzy parameters, such model becomes more realistic. During last two decades a lot of work related inventory problems have been done in fuzzy environments (cf. Jana et al. [15-17]). But when we dig into the uncertainty of a fuzzy set, there are two cases: the membership is also fuzzy and the element is also fuzzy. So there exist a level 2 fuzzy set and type 2 fuzzy set. The mathematical properties of fuzzy set of type 2 are investigated by Zadeh [18-20] and Mendel et al. [21]. The concept of level 2 fuzzy set was introduced by Zadeh [22] and was more elaborated by Gottwald [23]. Based on level 2 fuzzy set, Xu and Zhou [24] defined bifuzzy variable and they adopt the three models (i) bifuzzy EVM, (ii) bifuzzy CCM, and (iii) bifuzzy DCM to deal with multiobjective decision making models under bifuzzy environment [25].

In this paper we investigate a closed-loop system involving a manufacturing facility and a remanufacturing facility. The manufacturer satisfies stochastic market demand by remanufacturing the used product into "as-new" one and producing new products from raw material in the remanufacturing facility and the manufacturing facility, respectively. The remanufacturing cost depends on the quality of used product. The problem is maximizing the manufacturer's expected profit by jointly determining the collected quantity of used product and the ordered quantity of raw material. Following that we analyze the model with a fill rate constraint and a budget constraint separately and then with both the constraints. Next, to handle the imprecise nature of some parameters of the model, we develop the model with both constraints in bifuzzy environment. Finally numerical examples are presented to illustrate the models. The sensitivity analysis is also conducted to generate managerial insight.

\section{Bifuzzy Preliminaries}

2.1. Bifuzzy Set. A fuzzy set $\widetilde{V}$ over universal set $U$ is a set of ordered pair

$$
\widetilde{V}=\left\{\left(x, \mu_{\widetilde{V}}(x)\right) \mid \forall x \in U: \mu_{\widetilde{V}}(x)>0\right\},
$$

where membership function $\mu_{\widetilde{V}}$ is of the form

$$
\mu_{\widetilde{V}}: U \longrightarrow[0,1]
$$

Let the fuzzy set, as defined above, be called ordinary fuzzy set. Ordinary fuzzy set can successfully handle imperfect information of one single source, which is imprecise, uncertain, or vague. But the modelling facilities of fuzzy sets are limited to handle imperfect information of two or more sources of imperfection. Various generalizations of the concept "fuzzy set" have been discussed by researchers, which are "type 2 fuzzy set" and "level 2 fuzzy set." Type 2 fuzzy sets are fuzzy sets whose membership grades are themselves ordinary fuzzy sets. The membership function of a type 2 fuzzy set has the following form:

$$
\mu_{\widetilde{V}}: U \longrightarrow \widetilde{\wp}([0,1])
$$

where $\widetilde{\wp}([0,1])$ denotes the fuzzy power set of $[0,1]$. A level 2 fuzzy set $\widetilde{\widetilde{V}}$ is a fuzzy set whose elements are ordinary fuzzy sets. The membership function of a level 2 fuzzy set has the following form:

$$
\mu_{\widetilde{V}}: \widetilde{\wp}(U) \longrightarrow[0,1]
$$

where $\widetilde{\wp}(U)$ denotes the fuzzy power set of the universal set $U$. A formal definition of level 2 fuzzy set proposed by Gottwald [23] is given as follows. 
Definition 1. A level 2 fuzzy set $\widetilde{V}$ defined over a universal set $U$ is defined by

$$
\widetilde{\widetilde{V}}=\left\{\left(\widetilde{V}, \mu_{\widetilde{V}}(\widetilde{V})\right) \mid \forall \widetilde{V} \in \widetilde{\mathscr{g}}(U): \mu_{\widetilde{V}}(\widetilde{V})>0\right\},
$$

where each ordinary fuzzy set $\widetilde{V}$ is defined by

$$
\widetilde{V}=\left\{\left(x, \mu_{\widetilde{V}}(x)\right) \mid \forall x \in U: \mu_{\widetilde{V}}(x)>0\right\} .
$$

For convenience, the membership grades $\mu_{\widetilde{V}}(\widetilde{V})$ of the fuzzy sets $\widetilde{V} \in \widetilde{\wp}(U)$ are called "outer-layer" membership grades, whereas the membership grades $\mu_{\widetilde{V}}(x)$ of the element $x \in$ $U$ are called "inner-layer" membership grades. Normally speaking, a bifuzzy variable is a fuzzy variable with fuzzy parameters.

Example 2. $\tilde{\tilde{\xi}}=\left(\tilde{\xi}, \alpha_{1}, \beta_{1}\right)_{L R}$ with $\tilde{\xi}=\left(\xi, \alpha_{2}, \beta_{2}\right)_{L R}$ is called $L R$ bifuzzy variable, if the outer-layer and inner-layer membership function as follows:

$$
\begin{aligned}
& \mu_{\tilde{\xi}}(t)= \begin{cases}L\left(\frac{\tilde{\xi}-t}{\alpha_{1}}\right), & \tilde{\xi}-\alpha_{1} \leq t \leq \tilde{\xi}, \alpha_{1}>0 \\
R\left(\frac{t-\tilde{\xi}}{\beta_{1}}\right), & \tilde{\xi} \leq t \leq \tilde{\xi}+\beta_{1}, \beta_{1}>0,\end{cases} \\
& \mu_{\tilde{\xi}}(t)= \begin{cases}L\left(\frac{\xi-t}{\alpha_{2}}\right), & \xi-\alpha_{2} \leq t \leq \xi, \alpha_{2}>0 \\
R\left(\frac{t-\xi}{\beta_{2}}\right), & \xi \leq t \leq \xi+\beta_{2},\end{cases}
\end{aligned}
$$

where $\tilde{\xi}$ is center of $\widetilde{\xi}$, which is also a fuzzy number, $\alpha_{1}, \alpha_{2}, \beta_{1}, \beta_{2}$ are the left and right spread of $\tilde{\tilde{\xi}}$ and $\tilde{\xi}$, the basis functions $L(x), R(x)$ are continuous nonincreasing functions, and $L, R:[0,1] \rightarrow[0,1]$ satisfies that $L(1)=R(1)=0$, $L(0)=R(0)=1$.

$\alpha$ cut $\tilde{\xi}_{\alpha}$ of $L R$ bifuzzy variable $\tilde{\xi}_{\text {is }} \tilde{\xi}_{\alpha}=\left(\tilde{\xi}_{\alpha}^{L}, \widetilde{\xi}_{\alpha}^{R}\right)=[\tilde{\xi}-$ $\left.L^{-1}(\alpha) \alpha_{1}, \widetilde{\xi}+R^{-1}(\alpha) \beta_{1}\right]$.

2.2. Possibility Measure. Let $\Theta$ be a nonempty set and $P(\Theta)$ the power set of $\Theta$. For each $A \subseteq P(\Theta)$, there is a nonnegative number $\operatorname{Pos}\{A\}$ called its possibility such that

(1) $\operatorname{Pos}\{\phi\}=0$ and $\operatorname{Pos}\{\Theta\}=1$,

(2) $\operatorname{Pos}\left\{\cup_{k} A_{k}\right\}=\sup _{k} \operatorname{Pos}\left\{A_{k}\right\}$ for any arbitrary collection $\left\{A_{k}\right\}$ in $P(\Theta)$.

The triplet $\{\Theta, P(\Theta)$, Pos $\}$ is called possibility space and the function Pos is referred to as a possibility measure.

Lemma 3. Let $\widetilde{\xi}_{1}$ and $\widetilde{\xi}_{2}$ be two fuzzy variables; then

$$
\begin{aligned}
& \operatorname{Pos}\left\{\tilde{\xi}_{1} \geq \widetilde{\xi}_{2}\right\}=\sup \left\{\mu_{\widetilde{\xi}_{1}}(u) \wedge \mu_{\widetilde{\xi}_{2}}(v) \mid u>v\right\}, \\
& \operatorname{Pos}\left\{\widetilde{\xi}_{1}>\widetilde{\xi}_{2}\right\}=\sup \left\{\mu_{\widetilde{\xi}_{1}}(u) \wedge \inf _{v}\left\{1-\mu_{\widetilde{\xi}_{2}}(v)\right\} \mid u \leq v\right\} .
\end{aligned}
$$

By using the $\alpha$-level of fuzzy variables $\xi_{1}$ and $\xi_{2},\left[m_{\alpha}^{L}, m_{\alpha}^{R}\right]$, and $\left[n_{\alpha}^{L}, n_{\alpha}^{R}\right]$, Lemma 3 can be written as

$$
\begin{gathered}
\operatorname{Pos}\left\{\widetilde{\xi}_{1} \geq \widetilde{\xi}_{2}\right\} \geq \alpha \Longleftrightarrow m_{\alpha}^{R} \geq n_{\alpha}^{L}, \\
\operatorname{Pos}\left\{\widetilde{\xi}_{1}>\widetilde{\xi}_{2}\right\} \geq \alpha \Longleftrightarrow m_{\alpha}^{R} \geq n_{1-\alpha}^{R} .
\end{gathered}
$$

\subsubsection{Chance Operator of Bifuzzy Variables}

Definition 4 (Liu [26]). Let $\xi$ be a bifuzzy variable and $B$ a borel set of $R$. Then the primitive chance of bifuzzy event $\xi \epsilon$ $B$ is a function from $(0,1]$ to $[0,1]$, defined as

$$
\operatorname{Ch}\{\xi \in B\}(\alpha)=\sup _{\operatorname{Me}\{A\} \geq \alpha} \inf _{\theta \in A} \operatorname{Me}\{\xi(\theta) \in B\} .
$$

Usually, we use Pos or Nec to measure the chance of bifuzzy events.

Definition 5 (Xu and Zhou [24]). Let $\xi=\left\{\xi_{1}, \xi_{2}, \ldots, \xi_{n}\right\}$ be a bifuzzy vector defined on $\{\Theta, P(\Theta)$, Pos $\}$, and $f: R^{n} \rightarrow R$ is a real valued continuous function. Then the primitive chance of a bifuzzy event characterized by $f(\xi) \leq 0$ is a function from $(0,1]$ to $[0,1]$, defined as follows.

(1) Pos-Pos chance is

$$
\begin{aligned}
\operatorname{Ch} & \{f(\xi) \leq 0\}(\alpha) \\
& =\sup _{\alpha \in[0,1]}\{\theta \mid \operatorname{Pos}\{\theta \in \Theta \mid \operatorname{Pos}\{f(\xi(\theta)) \leq 0\} \geq \beta\} \geq \alpha\} .
\end{aligned}
$$

(2) Nec-Nec chance is

$$
\begin{aligned}
& \operatorname{Ch}\{f(\xi) \leq 0\}(\alpha) \\
& =\sup _{\alpha \in[0,1]}\{\theta \mid \operatorname{Nec}\{\theta \in \Theta \mid \operatorname{Nec}\{f(\xi(\theta)) \leq 0\} \geq \beta\} \geq \alpha\},
\end{aligned}
$$

where $\alpha, \beta \in[0,1]$ are predetermined confidence level.

2.3. Model for Bifuzzy CCM Based on Pos Measure. Let us consider the following single objective bifuzzy model:

$$
\begin{array}{ll}
\text { Max } & h(x, \xi) \\
\text { s.t } & g_{r}(x, \xi) \leq 0, \quad r=1,2, \ldots, p \\
& x \in X,
\end{array}
$$

where $\xi=\left(\xi_{1}, \xi_{2}, \ldots, \xi_{n}\right)$ is a bifuzzy vector and $x=$ $\left(x_{1}, x_{2}, \ldots, x_{n}\right)$ is a decision vector; then the objective function $h(x, \xi)$ and constraint functions $g_{r}(x, \xi)$ become bifuzzy variables, $r=1,2, \ldots, p$.

In order to obtain optimistic and pessimistic equivalent of bifuzzy model (13) we use the chance operator to transform the fuzzy uncertain model into the crisp model, which we called bifuzzy chance constrained model (bifuzzy CCM).

The general bifuzzy CCM is as follows:

$\operatorname{Max} w$

$$
\begin{array}{ll}
\text { s.t } & \operatorname{Ch}\{h(x, \xi) \geq w\}(\zeta) \geq \delta \\
& \operatorname{Ch}\left\{g_{r}(x, \xi) \leq 0\right\}\left(\eta_{r}\right) \geq \theta_{r}, \quad r=1,2, \ldots, p \\
& x \in X,
\end{array}
$$


where $\zeta, \delta, \eta, \theta$ are the predetermined confidence level and $w$ is the decision variable.

We adopt Pos to measure the fuzzy event; then the spectrum of chance constrained model based on Pos measure is as follow:

$$
\begin{array}{ll}
\text { Max } & w \\
\text { s.t } & \operatorname{Pos}\{\theta \mid \operatorname{Pos}\{h(x, \widetilde{\widetilde{\xi}}(\theta)) \geq w\} \geq \delta\} \geq \zeta \\
& \operatorname{Pos}\left\{\theta \mid \operatorname{Pos}\left\{g_{r}(x, \widetilde{\widetilde{\xi}}(\theta)) \leq 0\right\} \geq \theta_{r}\right\} \geq \eta_{r}, \\
r=1,2, \ldots, p,
\end{array}
$$

$x \in X$.

2.4. Linear Bifuzzy Model. For linear bifuzzy single objective function model, it is assumed that the combination of fuzzy variables is linear but not the decision making variable $x$; then the objective function and constraints are written as linear in bifuzzy variables. We consider the linear programming with bifuzzy parameters $\widetilde{\widetilde{c}}_{i}, \widetilde{\widetilde{e}}_{r j}, \widetilde{\widetilde{b}}_{r}$. Consider

$$
\begin{array}{ll}
\text { Max } & \widetilde{\widetilde{c}}^{T} h(x) \\
\text { s.t } & \widetilde{\widetilde{e}}_{r}^{T} g_{r}(x) \leq 0, \quad r=1,2, \ldots, p
\end{array}
$$

where $h(x)=\left(h_{1}(x), h_{2}(x), \ldots, h_{k}(x)\right)$ and $g(x)=\left(g_{r 1}(x)\right.$, $\left.g_{r 2}(x), \ldots, g_{r l}(x)\right)$ are $k$ dimensional and $l$ dimensional vectors, respectively.

2.4.1. Equivalent Crisp Model. Next, using the bifuzzy CCM based on Pos measure with the above model we can get the following model:

$$
\begin{array}{ll}
\text { Max } & w \\
\text { s.t } & \operatorname{Pos}\left\{\theta \mid \operatorname{Pos}\left\{\tilde{\widetilde{c}}(\theta)^{T} h(x) \geq w\right\} \geq \delta\right\} \geq \zeta \\
& \operatorname{Pos}\left\{\theta \mid \operatorname{Pos}\left\{\widetilde{\widetilde{e}}_{r}(\theta)^{T} g_{r}(x) \leq \widetilde{\widetilde{b}}_{r}(\theta)\right\} \geq \theta_{r}\right\} \geq \eta_{r}, \\
& \quad r=1,2, \ldots, p,
\end{array}
$$

In order to solve model (17), we apply the following two theorems to transform the chance constrained model into its crisp model based on Pos-Pos measure.

Theorem 6. Assume that $\tilde{\widetilde{c}}(\theta)=\left(\widetilde{\widetilde{c}}_{1}(\theta), \widetilde{\widetilde{c}}_{2}(\theta), \ldots, \widetilde{\widetilde{c}}_{k}(\theta)\right)^{T}$ is bifuzzy vector and $\widetilde{\widetilde{c}}_{i}(\theta)$ is LR bifuzzy variable denoted by $\widetilde{\widetilde{c}}_{i}(\theta)=\left(c_{i}(\theta), \alpha_{i 1}^{c}, \beta_{i 1}^{c}\right)_{L R}$ with fuzzy $c_{i}(\theta)=\left(c_{i}, \alpha_{i 2}^{c}, \beta_{i 2}^{c}\right)_{L R}$ for any $\theta \in \Theta$ and $h_{i}(x) \geq 0$. Then $\operatorname{Pos}\left\{\theta \mid \operatorname{Pos}\left\{\tilde{\widetilde{c}}(\theta)^{T} h(x) \geq w\right\} \geq\right.$ $\delta\} \geq \zeta$ is equivalent to

$$
c^{T} h(x)+R^{-1}(\delta) \beta_{1}^{c T} h(x)+R^{-1}(\zeta) \beta_{2}^{c T} h(x) \geq w
$$

where $\delta, \zeta \in[0,1]$ are predetermined confidence level.
Proof. For certain $\theta \in \Theta, \widetilde{\widetilde{c}}_{i}(\theta)$ are fuzzy number, and its member ship function is $\mu \tilde{\widetilde{c}}_{i}(\theta)(t)$. By extension principle, the membership function of fuzzy number $\widetilde{\widetilde{c}}(\theta)^{T} h(x)$ is

$$
\mu_{\tilde{c}(\theta)^{T} h(x)}(r)= \begin{cases}L\left(\frac{c(\theta)^{T} h(x)-r}{\alpha_{1}^{c T} h(x)}\right), & r \leq c(\theta)^{T} h(x) \\ R\left(\frac{r-c(\theta)^{T} h(x)}{\beta_{1}^{c T} h(x)}\right), & r \geq c(\theta)^{T} h(x) .\end{cases}
$$

For convenience, denote that $\tilde{\widetilde{c}}(\theta)^{T} h(x)=\left(c(\theta)^{T} h(x)\right.$, $\left.\alpha_{1}^{c T} h(x), \beta_{1}^{c T} h(x)\right)_{L R}$. Since $c(\theta)$ is also a $L R$ fuzzy vector, so $c(\theta)^{T} h(x)=\left(c^{T} h(x), \alpha_{2}^{c T} h(x), \beta_{2}^{c T} h(x)\right)_{L R}$. According to Lemma 3 we can get

$$
\begin{aligned}
\operatorname{Pos}\left\{\widetilde{\widetilde{c}}(\theta)^{T} h(x) \geq w\right\} & \geq \delta \Longleftrightarrow c(\theta)^{T} h(x)+R^{-1}(\delta) \beta_{1}^{c T} h(x) \\
& \geq w .
\end{aligned}
$$

So for predetermined level $\delta, \zeta \in[0,1]$

$$
\begin{aligned}
\operatorname{Pos} & \left\{\theta \mid \operatorname{Pos}\left\{\widetilde{\widetilde{c}}(\theta)^{T} h(x) \geq w\right\} \geq \delta\right\} \geq \zeta \\
& \Longleftrightarrow \operatorname{Pos}\left\{\theta \mid c(\theta)^{T} h(x) \geq w-R^{-1}(\delta) \beta_{1}^{c T} h(x)\right\} \geq \zeta \\
& \Longleftrightarrow c^{T} h(x)+R^{-1}(\delta) \beta_{1}^{c T} h(x)+R^{-1}(\zeta) \beta_{2}^{c T} h(x) \geq w .
\end{aligned}
$$

Theorem 7. Assume that $\widetilde{\widetilde{e}}_{r j}(\theta)$ and $\widetilde{\widetilde{b}}_{r}(\theta)$ are LR bifuzzy variables denoted by $\widetilde{\tilde{e}}_{r j}(\theta)=\left(e_{r j}(\theta), \alpha_{r j 1}^{e}, \beta_{r j 1}^{e}\right)_{L R}$ with fuzzy $e_{r j}(\theta)=\left(e_{r j}, \alpha_{r j 2}^{e}, \beta_{r j 2}^{e}\right)_{L R}$ and $\widetilde{\widetilde{b}}_{r}(\theta)=\left(b_{r}(\theta), \alpha_{r 1}^{b}, \beta_{r 1}^{b}\right)_{L R}$ with fuzzy $b_{r}(\theta)=\left(b_{r}, \alpha_{r 2}^{b}, \beta_{r 2}^{b}\right)_{L R}$ for $r=1,2, \ldots, p, j=1,2, \ldots, l$ and $g_{r j}(x) \geq 0$. Then $\operatorname{Pos}\left\{\theta \mid \operatorname{Pos}\left\{\tilde{\widetilde{e}}_{r}(\theta)^{T} g_{r}(x) \geq \widetilde{\widetilde{b}}_{r}(\theta)\right\} \geq\right.$ $\left.\theta_{r}\right\} \geq \eta_{r}$ is equivalent to

$$
\begin{aligned}
& R^{-1}\left(\theta_{r}\right) \beta_{r 1}^{b}+L^{-1}\left(\theta_{r}\right) \alpha_{r 1}^{e T} g_{r}(x)-e_{r}^{T} g_{r}(x)+b_{r} \\
& \quad+L^{-1}\left(\eta_{r}\right)\left(\alpha_{r 2}^{e T} g_{r}(x)+\beta_{r 2}^{b}\right) \geq 0 .
\end{aligned}
$$

Proof. The proof is similar to Theorem 6.

\section{Notations and Assumptions}

The Notations and Assumptions of the proposed models are given below:

\subsection{Assumption}

(i) The brand-new product and remanufactured product are sold at same selling price.

(ii) The return rate of used product is infinite. 


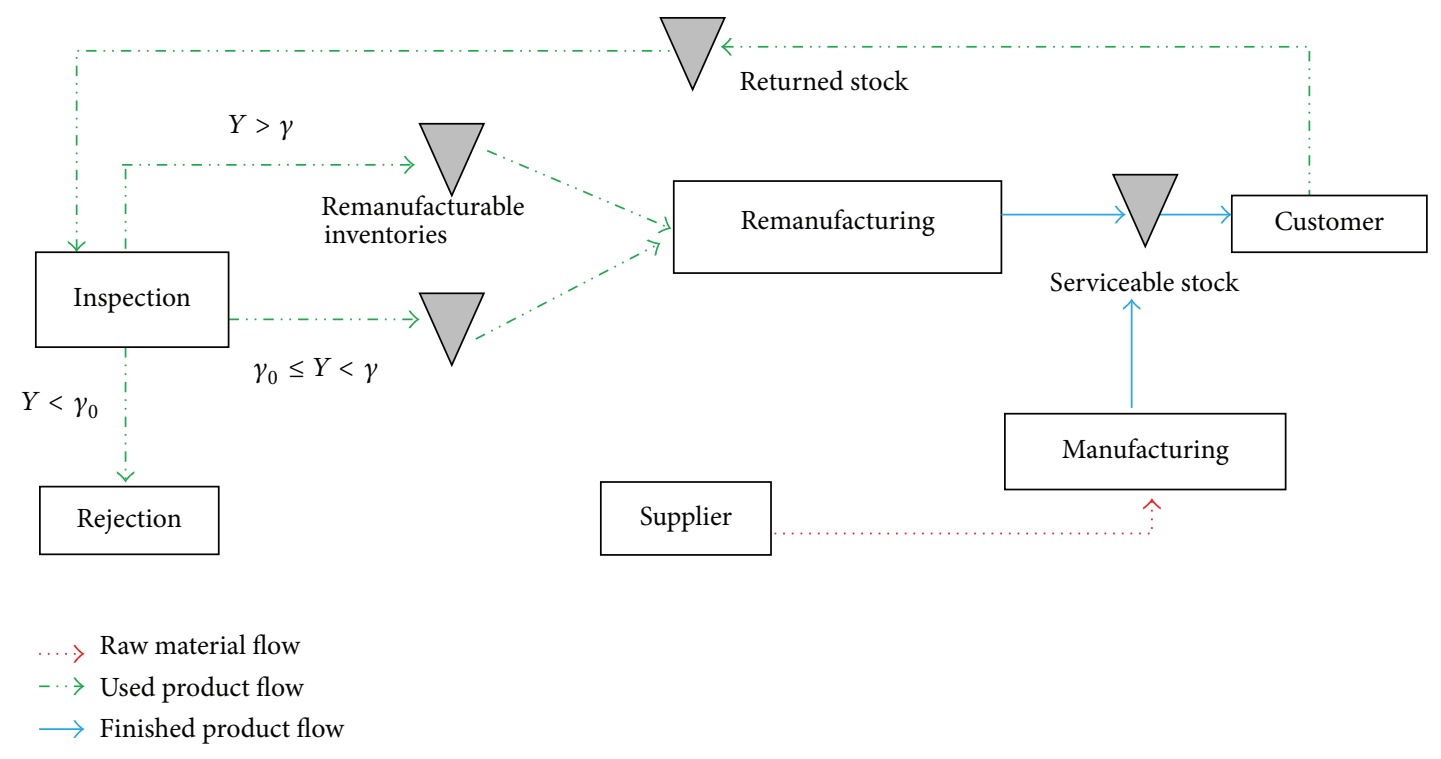

FIGURE 1: The frame work of the closed-loop system.

(iii) Remanufacturing cost depends on the quality of used product.

(iv) Storage capacities of raw material, used product, manufactured product, and remanufactured product are infinite.

(v) Lead time is zero.

\section{Model Description}

In this paper we study a closed-loop system involving a manufacturing facility and a remanufacturing facility. The manufacturer satisfies stochastic market demand by remanufacturing the used product into "as-new" one and producing new products from raw material. The manufacturer collects used items by offering low price to customer. In reality, the collected used items are of different qualities. In the remanufacturing facility, the used products are inspected carefully and sorted with respect to the quality of the used product. The products with good quality require less remanufacturing effort than the products, the quality level of which is below $\gamma$ but above $\gamma_{0}$ and the remaining used products are rejected. After sorting process, the used product is remanufactured into as-new product and stocked at serviceable inventory that is used to satisfy market demand. Most of the time, the remanufactured products can not satisfy all the demand. The manufacturer purchases raw material at high price. New products are produced at the manufacturing facility. Our objective is to maximize the manufacturer's expected profit by jointly determining the collected quantity of used product and the ordered quantity of raw material. The frame work of the system is presented in Figure 1.

\section{Models Formulation in Crisp Environment}

To formulate the problem, we first present the unconstrained model to evaluate the optimal order quantities. Following that we analyze the model with a fill rate constraint and a budget constraint separately and then with both the constraints.

5.1. Unconstrained Model (Model-1). Initially, when collected lot of used items confirms good quality standard, that is, quality of the used items satisfies GQL (with probability $G_{1}$ ), the associate expected profit per period $\operatorname{TP}_{1}\left(Q, Q_{0}\right)$ is

$$
\begin{aligned}
& \mathrm{TP}_{1}\left(Q, Q_{0}\right) \\
& =-c Q-i Q-c_{0} Q_{0} \\
& +\int_{f_{1} \mathrm{Q}+f_{0} \mathrm{Q}_{0}}^{\infty}\left[p\left(f_{1} Q+f_{0} Q_{0}\right)-s\left(x-f_{1} Q-f_{0} Q_{0}\right)\right] \\
& \quad \times f(x) d x \\
& \quad+\int_{0}^{f_{1} Q+f_{0} Q_{0}}\left[p x+r\left(f_{1} Q+f_{0} Q_{0}-x\right)\right] f(x) d x \\
& \quad-p_{1} Q-p_{0} Q_{0} .
\end{aligned}
$$

In the above expected profit function, the first term represents the acquisition price of used product. The second term is purchasing cost of raw material. The third term is the expected revenue minus the shortage cost when the demand is higher than production quantity; that is, $x>f_{1} Q+f_{0} Q_{0}$. The fourth term is the expected revenue plus the salvage cost when the demand is lower than production quantity; that is, $x<f_{1} Q+f_{0} Q_{0}$; the surplus stock can either be offered with a discount or sold to a secondary market at a unit salvage cost 
$r$, with $r<p$. The fifth term is remanufacturing cost of used items. The sixth term is manufacturing cost of raw material.

When the quality of collected lot of used items is below GQL but above RQL (with probability $G_{2}$ ), the associate expected profit per period $\operatorname{TP}_{2}\left(Q, Q_{0}\right)$ is

$$
\begin{aligned}
& \mathrm{TP}_{2}\left(Q, Q_{0}\right) \\
& =-c Q-i Q-c_{0} Q_{0} \\
& +\int_{f_{2} Q+f_{0} Q_{0}}^{\infty}\left[p\left(f_{2} Q+f_{0} Q_{0}\right)-s\left(x-f_{2} Q-f_{0} Q_{0}\right)\right] \\
& \times f(x) d x \\
& +\int_{0}^{f_{2} Q+f_{0} Q_{0}}\left[p x+r\left(f_{2} Q+f_{0} Q_{0}-x\right)\right] f(x) d x \\
& -p_{2} Q-p_{0} Q_{0} \text {. }
\end{aligned}
$$

Similarly, when the quality of collected lot of used items is below RQL (with probability $G_{3}$ ), the associate expected profit per period $\mathrm{TP}_{3}\left(Q, Q_{0}\right)$ is

$$
\begin{aligned}
\mathrm{TP}_{3}\left(Q, Q_{0}\right) \\
=-c Q-i Q-c_{0} Q_{0} \\
\quad+\int_{f_{0} Q_{0}}^{\infty}\left[p f_{0} Q_{0}-s\left(x-f_{0} Q_{0}\right)\right] f(x) d x \\
\quad+\int_{0}^{f_{0} Q_{0}}\left[p x+r\left(f_{0} Q_{0}-x\right)\right] f(x) d x-p_{0} Q_{0} .
\end{aligned}
$$

Therefore, combining all possible qualities of collected used items, the total weighted expected profit per period becomes

$$
\begin{aligned}
\operatorname{TP}\left(Q, Q_{0}\right)= & G_{1} \operatorname{TP}_{1}\left(Q, Q_{0}\right)+G_{2} \operatorname{TP}_{2}\left(Q, Q_{0}\right) \\
& +G_{3} T_{3}\left(Q, Q_{0}\right) .
\end{aligned}
$$

The value of $G_{1}, G_{2}$, and $G_{3}$ can be estimated from previous quality history. Our problem is

$$
\operatorname{Max} \operatorname{TP}\left(Q, Q_{0}\right) .
$$

Proposition 8. (a) The maximum value of $T P\left(Q, Q_{0}\right)$ for the problem (27) is attained for $Q^{*}$ and $Q_{0}^{*}$, by solving the following system of equations:

$$
\begin{aligned}
& (p+s)\left(G_{1} f_{1}+G_{2} f_{2}\right)+(r-p-s) \\
& \quad \times\left[G_{1} f_{1} F\left(f_{1} Q+f_{0} Q_{0}\right)+G_{2} f_{2} F\left(f_{2} Q+f_{0} Q_{0}\right)\right] \\
& =c+i+G_{1} p_{1}+G_{2} p_{2}, \\
& (p+s) f_{0}+(r-p-s) f_{0} \\
& \quad \times\left[G_{1} F\left(f_{1} Q+f_{0} Q_{0}\right)+G_{2} F\left(f_{2} Q+f_{0} Q_{0}\right)+G_{3} F\left(f_{0} Q_{0}\right)\right] \\
& =c_{0}+p_{0} .
\end{aligned}
$$
$Q_{0}$.

(b) The total expected profit $T P\left(Q, Q_{0}\right)$ is concave in $Q$ and
Proof. (a) The first order partial derivatives of (26) with respect to $Q$ and $Q_{0}$ are the following:

$$
\frac{\partial \mathrm{TP}\left(Q, Q_{0}\right)}{\partial Q}=0, \quad \frac{\partial \mathrm{TP}\left(Q, Q_{0}\right)}{\partial Q_{0}}=0,
$$

which give (28).

(b) The second order partial derivatives of (26) with respect to $Q$ and $Q_{0}$ are given below:

$$
\begin{aligned}
& \frac{\partial^{2} \mathrm{TP}\left(Q, Q_{0}\right)}{\partial Q^{2}} \\
& =-(p+s-r) \\
& \quad \times\left[G_{1} f_{1}^{2} f\left(f_{1} Q+f_{0} Q_{0}\right)+G_{2} f_{2}^{2}\left(f_{2} Q+f_{0} Q_{0}\right)\right] \\
& \quad \leq 0, \\
& \frac{\partial^{2} \mathrm{TP}\left(Q, Q_{0}\right)}{\partial Q_{0}^{2}} \\
& =-(p+s-r) f_{0}^{2} \\
& \times\left[G_{1} f\left(f_{1} Q+f_{0} Q_{0}\right)+G_{2} f\left(f_{2} Q+f_{0} Q_{0}\right)+G_{3} f\left(f_{0} Q_{0}\right)\right] \\
& \leq 0, \\
& \frac{\partial^{2} \mathrm{TP}\left(Q, Q_{0}\right)}{\partial Q \partial Q_{0}} \\
& =-(p+s-r) f_{0} \\
& \quad \times\left[G_{1} f_{1} f\left(f_{1} Q+f_{0} Q_{0}\right)+G_{2} f_{2} f\left(f_{2} Q+f_{0} Q_{0}\right)\right] \\
& \leq 0 .
\end{aligned}
$$

Next, the first $\left(\left|H_{1}\right|\right)$ and second $\left(\left|H_{2}\right|\right)$ order determinants of Hessian matrix are

$$
\left|H_{1}\right|=\frac{\partial^{2} \mathrm{TP}\left(Q, Q_{0}\right)}{\partial Q^{2}}<0,
$$

$$
\begin{aligned}
& \left|H_{2}\right| \\
& =\frac{\partial^{2} \mathrm{TP}\left(Q, Q_{0}\right)}{\partial Q^{2}} \frac{\partial^{2} \mathrm{TP}\left(Q, Q_{0}\right)}{\partial Q_{0}^{2}}-\left[\frac{\partial^{2} \mathrm{TP}\left(Q, Q_{0}\right)}{\partial Q \partial Q_{0}}\right]^{2} \\
& =f_{0}^{2}(p+s-r)^{2} \\
& \times\left[\left(f_{1}-f_{2}\right)^{2} G_{1} G_{2} f\left(f_{1} Q+f_{0} Q_{0}\right) f\left(f_{2} Q+f_{0} Q_{0}\right)\right. \\
& +G_{3} f\left(f_{0} Q_{0}\right) \\
& \left.\times\left[G_{1} f_{1}^{2} f\left(f_{1} Q+f_{0} Q_{0}\right)+G_{2} f_{2}^{2} f\left(f_{2} Q+f_{0} Q_{0}\right)\right]\right]
\end{aligned}
$$$$
>0 \text {. }
$$

Therefore, $\operatorname{TP}\left(Q, Q_{0}\right)$ is negative definite and thus concave in $Q$ and $Q_{0}$. 
5.2. Model with Fill Rate Constraint (Model-2). The market demand and quality of returned products are uncertain in the above model; thus the manufacturer has to face two types of overstocking and understocking risks. Under these circumstances, we analyze the problem of maximizing the expected overall profit of the hybrid system, subject to a fill rate-type customer-service level. Fill rate $\beta$ measures the part of stochastic demand that is met from finished new brand product. Consider

$$
\begin{aligned}
\beta & =1-\frac{\text { Expected number of stockout unit }}{\text { mean demand }} \\
& =1-\frac{S\left(Q, Q_{0}\right)}{\mu},
\end{aligned}
$$

where

$$
\begin{aligned}
S\left(Q, Q_{0}\right)= & G_{1} \int_{f_{1} Q+f_{0} Q_{0}}^{\infty}\left(x-f_{1} Q-f_{0} Q_{0}\right) f(x) d x \\
& +G_{2} \int_{f_{2} Q+f_{0} Q_{0}}^{\infty}\left(x-f_{2} Q-f_{0} Q_{0}\right) f(x) d x \\
& +G_{3} \int_{f_{0} Q_{0}}^{\infty}\left(x-f_{0} Q_{0}\right) f(x) d x .
\end{aligned}
$$

Hence, the resulting optimization model, which represents the maximization of total weighted expected profit subjected to a fill rate constraint, is

$$
\begin{array}{ll}
\operatorname{Max} & \operatorname{TP}\left(Q, Q_{0}\right) \\
\text { subject to } & \beta \geq \beta_{0} .
\end{array}
$$

Proposition 9. (a) The maximum value for problem (34) is attained for $Q^{*}, Q_{0}^{*}$, and $\lambda_{1}^{*}$ by solving the following system of equations:

$$
\begin{gathered}
\left(p+s+\frac{\lambda_{1}}{\mu}\right)\left(G_{1} f_{1}+G_{2} f_{2}\right)+\left(r-p-s-\frac{\lambda_{1}}{\mu}\right) \\
\quad \times\left[G_{1} f_{1} F\left(f_{1} Q+f_{0} Q_{0}\right)+G_{2} f_{2} F\left(f_{2} Q+f_{0} Q_{0}\right)\right] \\
=c+i+G_{1} p_{1}+G_{2} p_{2}, \\
\left(p+s+\frac{\lambda_{1}}{\mu}\right) f_{0}+\left(r-p-s-\frac{\lambda_{1}}{\mu}\right) f_{0} \\
\times\left[G_{1} F\left(f_{1} Q+f_{0} Q_{0}\right)+G_{2} F\left(f_{2} Q+f_{0} Q_{0}\right)+G_{3} F\left(f_{0} Q_{0}\right)\right] \\
=c_{0}+p_{0}, \\
\lambda_{1}\left(1-\frac{1}{\mu}\left[G_{1} \int_{f_{1} Q+f_{0} Q_{0}}^{\infty}\left(x-f_{1} Q-f_{0} Q_{0}\right) f(x) d x\right.\right. \\
+G_{2} \int_{f_{2} Q_{+} f_{0} Q_{0}}^{\infty}\left(x-f_{2} Q-f_{0} Q_{0}\right) f(x) d x \\
\left.\left.+G_{3} \int_{f_{0} Q_{0}}^{\infty}\left(x-f_{0} Q_{0}\right) f(x) d x\right]-\beta_{0}\right)=0 .
\end{gathered}
$$

(b) The problem (34) is a convex programming problem in $\mathrm{Q}$ and $\mathrm{Q}_{0}$.
Proof. (a) The Lagrangian relaxation of the problem $\left(P_{1}\right)$ is the following:

$$
\operatorname{Max} L_{1}\left(Q, Q_{0}, \lambda_{1}\right)
$$

where $L_{1}\left(Q, Q_{0}, \lambda_{1}\right)=\operatorname{TP}\left(Q, Q_{0}\right)+\lambda_{1} F_{1}\left(Q, Q_{0}\right)$ and $\lambda_{1}$ is the Lagrangian multiplier. Maximizing the above problem using Kuhn-Tucker conditions,

$$
\frac{\partial L_{1}}{\partial Q}=0, \quad \frac{\partial L_{1}}{\partial Q_{0}}=0, \quad \lambda_{1} \frac{\partial L_{1}}{\partial \lambda_{1}}=0,
$$

gives (35).

(b) The model $\left(P_{1}\right)$ will be a convex programming problem in $Q$ and $Q_{0}$, if the objective function to be maximized should be concave, while the fill rate constraint $\left(F_{1}=\beta-\right.$ $\left.\beta_{0}\right)$ should be concave. The objective function $\operatorname{TP}\left(Q, Q_{0}\right)$ is concave in $Q$ and $Q_{0}$.

The first $\left(\left|D_{1}\right|\right)$ and second $\left(\left|D_{2}\right|\right)$ order determinants of Hessian matrix $\nabla^{2} F_{1}\left(Q, Q_{0}\right)$ are

$$
\begin{aligned}
\left|D_{1}\right|= & \frac{\partial^{2} F_{1}\left(Q, Q_{0}\right)}{\partial Q^{2}} \\
= & -\frac{1}{\mu} \\
& \times\left[G_{1} f_{1}^{2} f\left(f_{1} Q+f_{0} Q_{0}\right)+G_{2} f_{2}^{2} f\left(f_{2} Q+f_{0} Q_{0}\right)\right] \\
< & 0, \\
\left|D_{2}\right|= & \frac{\partial^{2} F_{1}\left(Q, Q_{0}\right)}{\partial Q^{2}} \frac{\partial^{2} F_{1}\left(Q, Q_{0}\right)}{\partial Q_{0}^{2}}-\left[\frac{\partial^{2} F_{1}\left(Q, Q_{0}\right)}{\partial Q \partial Q_{0}}\right]^{2} \\
= & \frac{1}{\mu^{2}}\left[G _ { 3 } f _ { 0 } ^ { 2 } f ( f _ { 0 } Q _ { 0 } ) \left(G_{1} f_{1}^{2} f\left(f_{1} Q+f_{0} Q_{0}\right)\right.\right. \\
& \quad+G_{1} G_{2} f_{0}^{2} f\left(f_{1} Q+f_{0} Q_{0}\right) \\
& \left.\times f\left(f_{2} Q+f_{0} Q_{0}\right)\left(f_{1}-f_{2}\right)^{2}\right]>0 .
\end{aligned}
$$

As a result, $F_{1}\left(Q, Q_{0}\right)$ is negative definite and thus concave in $Q$ and $Q_{0}$; therefore the model $P_{1}$ is a convex programming problem.

5.3. Model with Budget Constraint (Model-3). In this section we maximize the manufacturer's expected profit by jointly determining the collected quantity of used product and the ordered quantity of raw material subject to a budget constraint. If $B$ is the available budget amount for purchasing used product and raw material and converting them to new product, then problem is reduced to

$$
\operatorname{Max} \quad \mathrm{TP}\left(Q, Q_{0}\right)
$$

subject to $c Q+i Q+c_{0} Q_{0}+G_{1} p_{1} Q+G_{2} p_{2} Q+p_{0} Q_{0} \leq B$. 
Proposition 10. The maximum value for problem (39) is attained for $Q^{*}, Q_{0}^{*}$, and $\lambda_{2}^{*}$ by solving the following system of equations:

$$
\begin{aligned}
(p+s) & \left(G_{1} f_{1}+G_{2} f_{2}\right)+(r-p-s) \\
& \times\left[G_{1} f_{1} F\left(f_{1} Q+f_{0} Q_{0}\right)+G_{2} f_{2} F\left(f_{2} Q+f_{0} Q_{0}\right)\right] \\
& =\left(1+\lambda_{2}\right)\left(c+i+G_{1} p_{1}+G_{2} p_{2}\right), \\
(p+s) f_{0}+(r-p-s) f_{0} & \\
\times & {\left[G_{1} F\left(f_{1} Q+f_{0} Q_{0}\right)+G_{2} F\left(f_{2} Q+f_{0} Q_{0}\right)+G_{3} F\left(f_{0} Q_{0}\right)\right] } \\
= & \left(1+\lambda_{2}\right)\left(c_{0}+p_{0}\right), \\
\lambda_{2} & \left(B-i Q-c Q-c_{0} Q_{0}-G_{1} p_{1} Q-G_{2} p_{2} Q-p_{0} Q_{0}\right)=0 .
\end{aligned}
$$

Proof. The Lagrangian relaxation of the problem (39) is the following:

$$
\operatorname{Max} L_{2}\left(Q, Q_{0}, \lambda_{2}\right) \text {, }
$$

where $L_{2}\left(Q, Q_{0}, \lambda_{2}\right)=\mathrm{TP}\left(Q, Q_{0}\right)+\lambda_{2}\left(B-c Q-i Q-c_{0} Q_{0}-\right.$ $\left.G_{1} p_{1} Q-G_{2} p_{2} Q-p_{0} Q_{0}\right)$ and $\lambda_{2}$ is the Lagrangian multiplier. Maximizing the above problem using Kuhn-Tucker conditions,

$$
\frac{\partial L_{2}}{\partial Q}=0, \quad \frac{\partial L_{2}}{\partial Q_{0}}=0, \quad \lambda_{2} \frac{\partial L_{2}}{\partial \lambda_{2}}=0,
$$

gives (40).

5.4. Model with Both Fill Rate and Budget Constraint (Model4). In this section we maximize the manufacturer's expected profit subject to a fill rate constraint and a budget constraint and the problem reduces to

$$
\begin{array}{ll}
\text { Max } & \mathrm{TP}\left(Q, Q_{0}\right) \\
\text { subject to } & \beta-\beta_{0} \geq 0 \\
& B-c Q-i Q-c_{0} Q_{0}-G_{1} p_{1} Q \\
& -G_{2} p_{2} Q-p_{0} Q_{0} \geq 0 .
\end{array}
$$

Proposition 11. (a) The maximum value for problem (43) is attained for $Q^{*}, Q_{0}^{*}, \lambda_{1}$, and $\lambda_{2}^{*}$ by solving the following system of equations:

$$
\begin{aligned}
(p+ & \left.s+\frac{\lambda_{1}}{\mu}\right)\left(G_{1} f_{1}+G_{2} f_{2}\right)+\left(r-p-s-\frac{\lambda_{1}}{\mu}\right) \\
& \times\left[G_{1} f_{1} F\left(f_{1} Q+f_{0} Q_{0}\right)+G_{2} f_{2} F\left(f_{2} Q+f_{0} Q_{0}\right)\right] \\
= & \left(1+\lambda_{2}\right)\left(c+i+G_{1} p_{1}+G_{2} p_{2}\right),
\end{aligned}
$$

$$
\begin{aligned}
& \left(p+s+\frac{\lambda_{1}}{\mu}\right) f_{0}+\left(r-p-s-\frac{\lambda_{1}}{\mu}\right) f_{0} \\
& \times\left[G_{1} F\left(f_{1} Q+f_{0} Q_{0}\right)+G_{2} F\left(f_{2} Q+f_{0} Q_{0}\right)+G_{3} F\left(f_{0} Q_{0}\right)\right] \\
& =\left(1+\lambda_{2}\right)\left(c_{0}+p_{0}\right), \\
& \lambda_{1}\left(1-\frac{1}{\mu}\left[G_{1} \int_{f_{1} Q+f_{0} Q_{0}}^{\infty}\left(x-f_{1} Q-f_{0} Q_{0}\right) f(x) d x\right.\right. \\
& \quad+G_{2} \int_{f_{2} Q+f_{0} Q_{0}}^{\infty}\left(x-f_{2} Q-f_{0} Q_{0}\right) f(x) d x \\
& \left.\left.\quad+G_{3} \int_{f_{0} Q_{0}}^{\infty}\left(x-f_{0} Q_{0}\right) f(x) d x\right]-\beta_{0}\right)=0, \\
& \lambda_{2}\left(B-c Q-i Q-c_{0} Q_{0}-G_{1} p_{1} Q-G_{2} p_{2} Q-p_{0} Q_{0}\right)=0 .
\end{aligned}
$$

Proof. The Lagrangian relaxation of the problem (43) is the following:

$$
\operatorname{Max} L_{12}\left(Q, Q_{0}, \lambda_{1}, \lambda_{2}\right),
$$

where $L_{12}\left(Q, Q_{0}, \lambda_{1}, \lambda_{2}\right)=\operatorname{TP}\left(Q, Q_{0}\right)+\lambda_{1}\left(\beta-\beta_{0}\right)+\lambda_{2}(B-$ $\left.c Q-i Q-c_{0} Q_{0}-G_{1} p_{1} Q-G_{2} p_{2} Q-p_{0} Q_{0}\right)$ and $\lambda_{2}$ is the Lagrangian multiplier. Maximizing the above problem using Kuhn-Tucker conditions,

$$
\frac{\partial L_{12}}{\partial Q}=0, \quad \frac{\partial L_{12}}{\partial Q_{0}}=0, \quad \lambda_{1} \frac{\partial L_{12}}{\partial \lambda_{1}}, \quad \lambda_{2} \frac{\partial L_{12}}{\partial \lambda_{2}}=0,
$$

gives (44).

\section{Models in Bifuzzy Environments}

To handle the imprecise nature of the parameters $\gamma, \gamma_{0}, \beta_{0}$, and $B$ of the above models, we have developed the models in bifuzzy environment.

And the bifuzzy variables are triangular $L R$ bifuzzy numbers and denoted by

$$
\begin{aligned}
& \tilde{\widetilde{\gamma}}(\theta)=\left(\gamma(\theta), \alpha_{11}, \beta_{11}\right)_{L R} \quad \text { with } \gamma(\theta)=\left(\gamma, \alpha_{12}, \beta_{12}\right) \text {, } \\
& \tilde{\tilde{\gamma}}_{0}(\theta)=\left(\gamma_{0}(\theta), \alpha_{21}, \beta_{21}\right)_{L R} \text { with } \gamma_{0}(\theta)=\left(\gamma_{0}, \alpha_{22}, \beta_{22}\right) \text {, } \\
& \widetilde{\widetilde{\beta}}_{0}(\theta)=\left(\beta_{0}(\theta), \alpha_{31}, \beta_{31}\right)_{L R} \quad \text { with } \beta_{0}(\theta)=\left(\beta_{0}, \alpha_{32}, \beta_{32}\right) \text {, } \\
& \widetilde{\widetilde{B}}(\theta)=\left(B(\theta), \alpha_{41}, \beta_{41}\right)_{L R} \quad \text { with } B(\theta)=\left(B, \alpha_{42}, \beta_{42}\right) \text {. }
\end{aligned}
$$

6.1. Unconstraint Model (Model-5). In this section, $\widetilde{\tilde{\gamma}}$ and $\widetilde{\tilde{\gamma}}_{0}$ are assumed to be bifuzzy variables. Then the constraints and 
objective function can be expressed in bifuzzy in nature as follows:

$$
\begin{aligned}
& \operatorname{Max} \underset{\widetilde{\mathrm{TP}}}{\widetilde{Q}}\left(Q, Q_{0}\right)=\frac{b}{b-a} \mathrm{TP}_{1}\left(Q, Q_{0}\right)-\frac{a}{b-a} \mathrm{TP}_{3}\left(Q, Q_{0}\right) \\
& -\frac{\tilde{\widetilde{\gamma}}}{b-a}\left(\mathrm{TP}_{1}\left(Q, Q_{0}\right)-\mathrm{TP}_{2}\left(\mathrm{Q}, \mathrm{Q}_{0}\right)\right) \\
& -\frac{\widetilde{\widetilde{\gamma}}_{0}}{b-a}\left(\mathrm{TP}_{2}\left(Q, Q_{0}\right)-\mathrm{TP}_{3}\left(Q, Q_{0}\right)\right) \text {. }
\end{aligned}
$$

6.1.1. Equivalent Crisp Model. In order to solve model (48), we use bifuzzy CCM based on Pos measure; then we can get the following model:

$$
\begin{array}{cl}
\text { Max } & w \\
\text { subject to } \operatorname{Pos}\left\{\theta \mid \operatorname{Pos}\left\{\frac{b}{b-a} \mathrm{TP}_{1}\left(Q, Q_{0}\right)\right.\right. \\
& -\frac{a}{b-a} \mathrm{TP}_{3}\left(Q, Q_{0}\right) \\
& \times \frac{\tilde{\widetilde{\gamma}}(\theta)}{b-a} \\
& \times\left(\mathrm{TP}_{1}\left(Q, Q_{0}\right)\right. \\
& \left.-\mathrm{TP}_{2}\left(Q, Q_{0}\right)\right) \\
& -\frac{\widetilde{\tilde{\gamma}}_{0}(\theta)}{b-a} \\
& \times\left(\mathrm{TP}_{2}\left(Q, Q_{0}\right)\right. \\
& \left.-\mathrm{TP}_{3}\left(Q, Q_{0}\right)\right) \\
& \geq w\} \geq \delta\} \geq \zeta .
\end{array}
$$

Then by Theorems 6 and 7 based on Pos-Pos measure we convert the above model to equivalent crisp model:

$$
\operatorname{Max} \quad w
$$

subject to $b \mathrm{TP}_{1}\left(\mathrm{Q}, \mathrm{Q}_{0}\right)-a \mathrm{TP}_{3}\left(\mathrm{Q}, \mathrm{Q}_{0}\right)$

$$
\begin{aligned}
& \geq(b-a) w \\
& \quad+\left(\gamma-\alpha_{11} L^{-1}(\delta)-\alpha_{12} L^{-1}(\zeta)\right) \\
& \quad \times\left(\mathrm{TP}_{1}\left(Q, Q_{0}\right)-\mathrm{TP}_{2}\left(Q, Q_{0}\right)\right) \\
& \quad+\left(\gamma_{0}-\alpha_{21} L^{-1}(\delta)-\alpha_{22} L^{-1}(\zeta)\right) \\
& \quad \times\left(\mathrm{TP}_{2}\left(Q, Q_{0}\right)-\mathrm{TP}_{3}\left(Q, Q_{0}\right)\right) .
\end{aligned}
$$

6.2. Model with Fill Rate Constraint (Model-6). In this section, $\widetilde{\widetilde{\gamma}}, \widetilde{\widetilde{\gamma}}_{0}$, and $\widetilde{\widetilde{\beta}}_{0}$ are assumed to be bifuzzy variables. Then the constraints and objective function can be expressed in bifuzzy in nature as follows:

$\operatorname{Max}(48)$

$$
\begin{aligned}
& \text { subject to } 1-\frac{b}{\mu(b-a)} \mathrm{SU}_{1}\left(Q, Q_{0}\right) \\
& +\frac{a}{\mu(b-a)} S_{3}\left(Q, Q_{0}\right) \\
& -\frac{\tilde{\tilde{\gamma}}}{\mu(b-a)}\left(\mathrm{SU}_{2}\left(Q, Q_{0}\right)-\mathrm{SU}_{1}\left(Q, Q_{0}\right)\right) \\
& -\frac{\widetilde{\widetilde{\gamma}}_{0}}{\underset{\sim}{\mu}(b-a)}\left(\mathrm{SU}_{3}\left(Q, Q_{0}\right)-\mathrm{SU}_{2}\left(Q, Q_{0}\right)\right) \\
& -\widetilde{\widetilde{\beta}}_{0} \geq 0 \text {, }
\end{aligned}
$$

where

$$
\begin{aligned}
& \mathrm{SU}_{1}\left(Q, Q_{0}\right)=\int_{f_{1} \mathrm{Q}+f_{0} \mathrm{Q}_{0}}^{\infty}\left(x-f_{1} \mathrm{Q}-f_{0} \mathrm{Q}_{0}\right) f(x) d x, \\
& \mathrm{SU}_{2}\left(Q, Q_{0}\right)=\int_{f_{2} \mathrm{Q}+f_{0} \mathrm{Q}_{0}}^{\infty}\left(x-f_{2} \mathrm{Q}-f_{0} \mathrm{Q}_{0}\right) f(x) d x, \\
& \mathrm{SU}_{3}\left(Q, Q_{0}\right)=\int_{f_{0} \mathrm{Q}_{0}}^{\infty}\left(x-f_{0} \mathrm{Q}_{0}\right) f(x) d x .
\end{aligned}
$$

6.2.1. Equivalent Crisp Model. In order to solve the above model we use bifuzzy CCM based on Pos measure; then we can get the following model:

$$
\begin{gathered}
\text { Max } w \\
\text { subject to }(50)
\end{gathered}
$$

$$
\begin{aligned}
\operatorname{Pos}\{\theta \mid \operatorname{Pos}\{1 & -\frac{b}{\mu(b-a)} \mathrm{SU}_{1}\left(Q, Q_{0}\right) \\
& +\frac{a}{\mu(b-a)} \mathrm{SU}_{3}\left(Q, Q_{0}\right) \\
& \geq \frac{\tilde{\widetilde{\gamma}}(\theta)}{\mu(b-a)} \\
& \times\left(\mathrm{SU}_{2}\left(Q, Q_{0}\right)\right. \\
& \left.-\mathrm{SU}_{1}\left(Q, Q_{0}\right)\right) \\
& +\frac{\widetilde{\widetilde{\gamma}}_{0}(\theta)}{\mu(b-a)} \\
& \times\left(\mathrm{SU}_{3}\left(Q, Q_{0}\right)\right. \\
& \left.-\mathrm{SU}_{2}\left(Q, Q_{0}\right)\right) \\
& \left.\left.+\widetilde{\widetilde{\beta}}_{0}(\theta)\right\} \geq \theta_{1}\right\} \geq \eta_{1} .
\end{aligned}
$$


Then by Theorems 6 and 7 based on Pos-Pos measure we convert the above model to equivalent crisp model:

$\operatorname{Max} \quad w$

subject to

$$
\begin{aligned}
\mu & (b-a)-b \mathrm{SU}_{1}\left(Q, Q_{0}\right)+a \mathrm{SU}_{3}\left(Q, Q_{0}\right) \\
\geq & \left(\gamma-\alpha_{11} L^{-1}\left(\theta_{1}\right)-\alpha_{12} L^{-1}\left(\eta_{1}\right)\right) \\
\times & \left(\mathrm{SU}_{2}\left(Q, Q_{0}\right)\right. \\
& \left.\quad-\mathrm{SU}_{1}\left(Q, Q_{0}\right)\right) \\
+ & \left(\gamma_{0}-\alpha_{21} L^{-1}\left(\theta_{1}\right)-\alpha_{22} L^{-1}\left(\eta_{1}\right)\right) \\
\times & \left(\mathrm{SU}_{3}\left(Q, Q_{0}\right)-\mathrm{SU}_{2}\left(\mathrm{Q}, \mathrm{Q}_{0}\right)\right) \\
+ & \mu(b-a) \\
\times & \left(\beta_{0}-\alpha_{31} L^{-1}\left(\theta_{1}\right)-\alpha_{32} L^{-1}\left(\eta_{1}\right)\right) .
\end{aligned}
$$

6.3. Model with Budget Constraint (Model-7). In this section, $\widetilde{\widetilde{\gamma}}, \widetilde{\widetilde{\gamma}}_{0}$, and $\widetilde{\widetilde{B}}$ are assumed to be bifuzzy variables. Then the constraints and objective function can be expressed in bifuzzy in nature as follows:

$\operatorname{Max}$

subject to

$$
\begin{aligned}
& \tilde{\widetilde{B}}-c Q-i Q-c_{0} Q_{0}-\frac{b}{b-a} \\
& \times p_{1} Q-\frac{\tilde{\widetilde{\gamma}}}{b-a} Q\left(p_{2}-p_{1}\right) \\
& +\frac{\widetilde{\widetilde{\gamma}}_{0}}{b-a} p_{2} Q-p_{0} Q_{0} \geq 0 .
\end{aligned}
$$

6.3.1. Equivalent Crisp Model. In order to solve the above model we use bifuzzy CCM based on Pos measure; then we can get the following model:

$\operatorname{Max} w$

subject to $(50)$

$$
\begin{aligned}
\operatorname{Pos}\left\{\theta \mid \operatorname{Pos}\left\{\tilde{\widetilde{B}}(\theta)+\frac{\widetilde{\widetilde{\gamma}}_{0}(\theta)}{b-a} p_{2} Q\right.\right. \\
\geq c Q+i Q+c_{0} Q_{0} \\
+\frac{b}{b-a} p_{1} Q+p_{0} Q_{0} \\
\left.+\frac{\tilde{\widetilde{\gamma}}(\theta)}{b-a} Q\left(p_{2}-p_{1}\right)\right\} \\
\left.\geq \theta_{2}\right\} \geq \eta_{2} .
\end{aligned}
$$

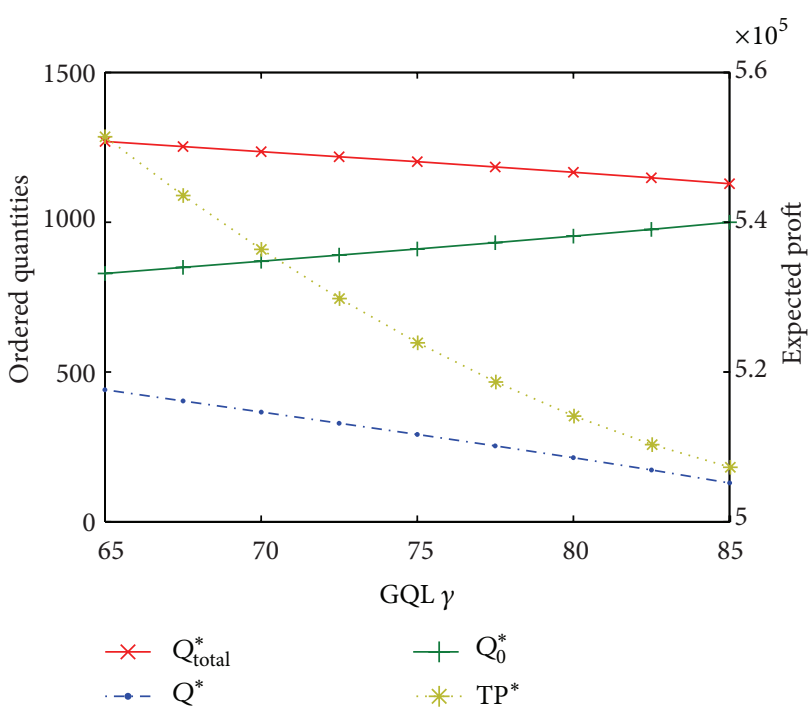

FIGURE 2: Effect of $\gamma$ on the optimal policy.

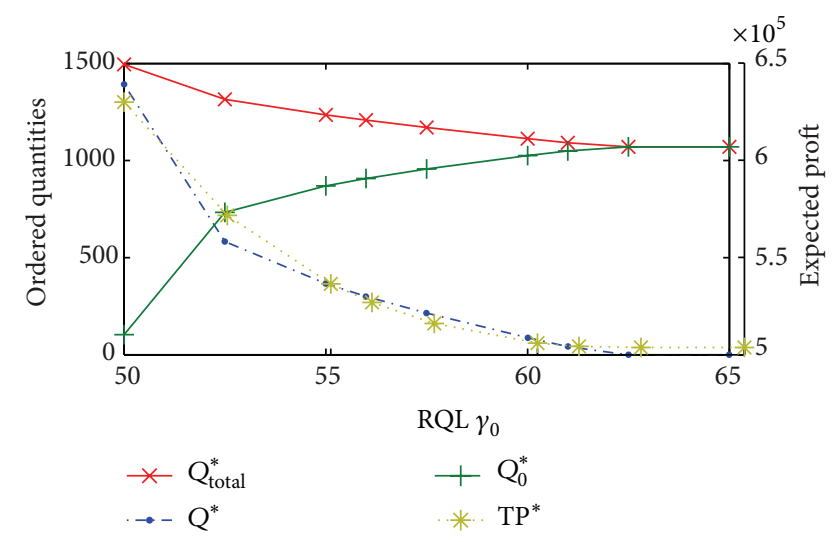

FIGURE 3: Effect of $\gamma_{0}$ on the optimal policy.

Then by Theorems 6 and 7 based on Pos-Pos measure we convert the above model to equivalent crisp model:

$\operatorname{Max} w$

subject to (52)

$$
\begin{aligned}
(b-a) & \left(B+\beta_{41} R^{-1}\left(\theta_{2}\right)+\beta_{42} R^{-1}\left(\eta_{2}\right)\right) \\
+ & p_{2} Q\left(\gamma_{0}+\beta_{21} R^{-1}\left(\theta_{2}\right)+\beta_{22} R^{-1}\left(\eta_{2}\right)\right) \\
\geq & (b-a)\left(c Q+i Q+c_{0} Q_{0}+p_{0} Q_{0}\right) \\
+ & b p_{1} Q+Q\left(p_{2}-p_{1}\right) \\
& \times\left(\gamma-\alpha_{11} L^{-1}\left(\theta_{2}\right)-\alpha_{12} L^{-1}\left(\eta_{2}\right)\right) .
\end{aligned}
$$

6.4. Model with Fill Rate Constraint and Budget Constraint (Model-8). In this section, $\widetilde{\widetilde{\gamma}}, \widetilde{\widetilde{\gamma}}_{0}, \widetilde{\widetilde{B}}$, and $\widetilde{\widetilde{\beta}}_{0}$ are assumed to be 


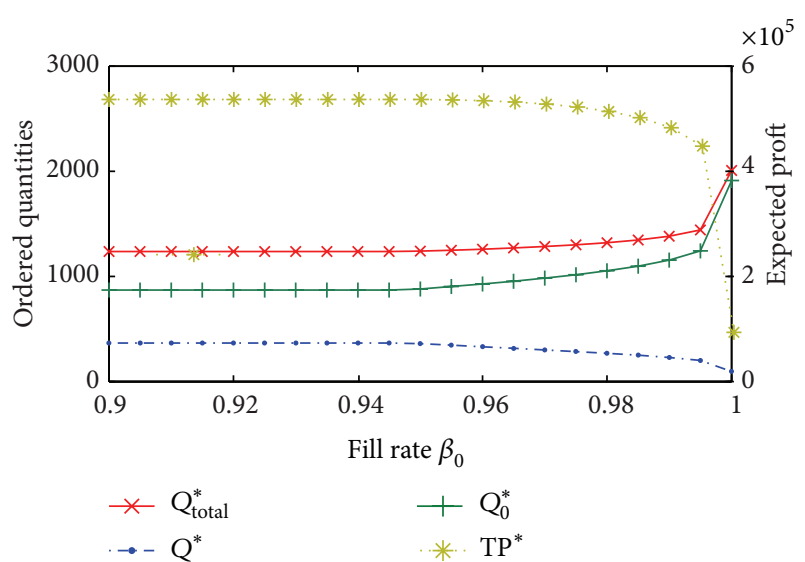

FIGURE 4: Effect of $\beta_{0}$ on the optimal policy.

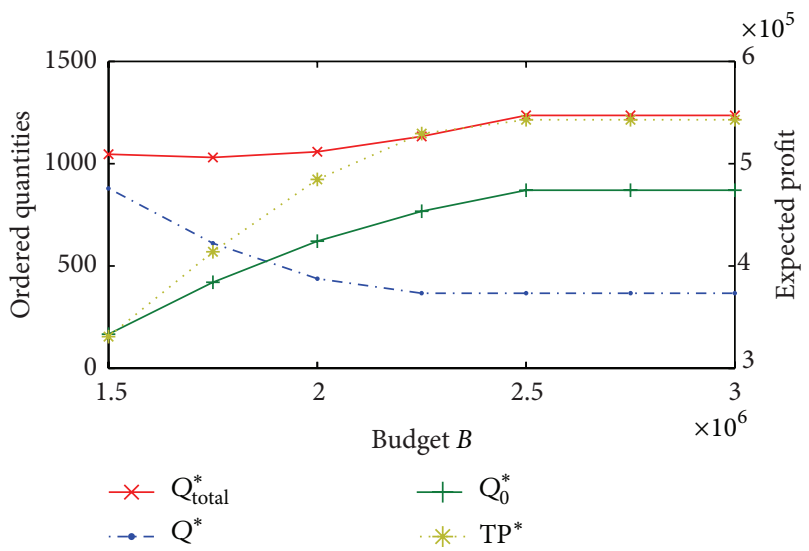

FIGURE 5: Effect of $B$ on the optimal policy.

bifuzzy variables. Then the constraints and objective function can be expressed in bifuzzy in nature as follows:

$$
\begin{aligned}
& \operatorname{Max}(48) \\
& \text { subject to }(54),(63) .
\end{aligned}
$$

6.4.1. Equivalent Crisp Model. In order to solve the above model we use bifuzzy CCM based on Pos measure; then we can get the following model:

$$
\begin{array}{ll}
\operatorname{Max} & w \\
\text { subject to }(50),(58),(66) .
\end{array}
$$

Then by Theorems 6 and 7 based on Pos-Pos measure we convert the above model to equivalent crisp model:

$$
\begin{array}{ll}
\text { Max } & w \\
\text { subject to } & (52),(61),(69) .
\end{array}
$$

\section{Numerical Examples}

We have solved the above models using gradient based nonlinear soft computing optimization technique (LINGO14.0).

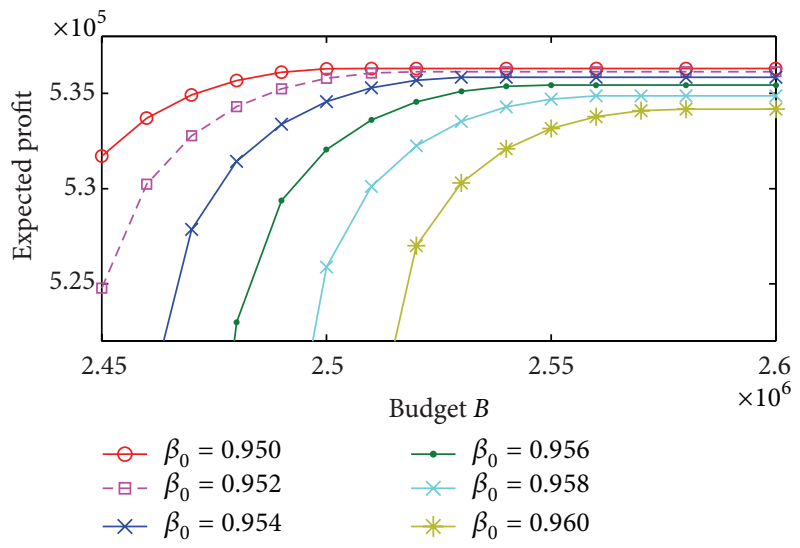

FIgURE 6: Effect of budget $B$ for different values of $\beta_{0}$ on the total profit.

TABLE 1: The optimal results of the models.

\begin{tabular}{lcccc}
\hline Problem & $Q^{*}$ & $Q_{0}^{*}$ & $Q_{\text {total }}^{*}$ & $\mathrm{TP}^{*}$ \\
\hline Model-1 & 365.88 & 869.55 & 1235.43 & 536382 \\
Model-2 & 359.30 & 879.87 & 1239.17 & 536313 \\
Model-3 & 360.92 & 851.25 & 1212.18 & 535867 \\
Model-4 & 183.58 & 947.54 & 1131.12 & 528142 \\
\hline
\end{tabular}

TABLE 2: Effect of changing $\gamma$ on the optimal policy.

\begin{tabular}{lcccc}
\hline$\gamma$ & $Q^{*}$ & $Q_{0}^{*}$ & $Q_{\text {total }}^{*}$ & $\mathrm{TP}^{*}$ \\
\hline 65 & 440.58 & 828.85 & 1269.43 & 551394 \\
70 & 365.88 & 869.55 & 1235.43 & 536382 \\
75 & 291.13 & 910.57 & 1201.71 & 523908 \\
80 & 213.42 & 953.30 & 1166.72 & 514115 \\
85 & 129.09 & 999.62 & 1128.72 & 507288 \\
\hline
\end{tabular}

TABLE 3: Effect of changing $\gamma_{0}$ on the optimal policy.

\begin{tabular}{lcccc}
\hline$\gamma_{0}$ & $Q^{*}$ & $Q_{0}^{*}$ & $Q_{\text {total }}^{*}$ & $\mathrm{TP}^{*}$ \\
\hline 50 & 1392.03 & 102.85 & 1494.88 & 629928 \\
52.5 & 582.06 & 733.62 & 1315.69 & 571682 \\
55 & 365.88 & 869.55 & 1235.43 & 536381 \\
57.5 & 213.96 & 956.85 & 1170.81 & 516091 \\
60 & 88.10 & 1024.94 & 1113.03 & 505960 \\
62.5 & 0.00 & 1070.63 & 1070.63 & 503739 \\
65 & 0.00 & 1070.63 & 1070.63 & 503739 \\
\hline
\end{tabular}

TABLE 4: Effect of changing $\beta_{0}$ on the optimal policy.

\begin{tabular}{lcccc}
\hline$\beta_{0}$ & $Q^{*}$ & $Q_{0}^{*}$ & $Q_{\text {total }}^{*}$ & $\mathrm{TP}^{*}$ \\
\hline 0.90 & 365.88 & 869.55 & 1235.43 & 536381 \\
0.92 & 365.88 & 869.55 & 1235.43 & 536381 \\
0.94 & 365.88 & 869.55 & 1235.43 & 536381 \\
0.96 & 330.65 & 927.41 & 1258.06 & 534172 \\
0.98 & 267.71 & 1052.24 & 1319.96 & 513907 \\
1.00 & 95.52 & 1912.28 & 2007.80 & 93471 \\
\hline
\end{tabular}

7.1. Crisp Models (Model-1 to -4). The mathematical behavior of proposed models is illustrated with the parameters $p=$ $3500, p_{1}=500, p_{2}=550, p_{0}=530, f_{1}=0.84, f_{2}=0.70$, 
TABLE 5: Effect of changing $B$ on the optimal policy.

\begin{tabular}{lcccc}
\hline$B$ & $Q^{*}$ & $Q_{0}^{*}$ & $Q_{\text {total }}^{*}$ & $\mathrm{TP}^{*}$ \\
\hline 1500000 & 879.56 & 166.25 & 1045.81 & 329976 \\
1750000 & 610.26 & 419.75 & 1030.01 & 410716 \\
2000000 & 437.20 & 621.00 & 1058.20 & 479685 \\
2250000 & 365.74 & 767.09 & 1132.84 & 523289 \\
2500000 & 365.88 & 869.55 & 1235.43 & 536382 \\
2750000 & 365.88 & 869.55 & 1235.43 & 536382 \\
3000000 & 365.88 & 869.55 & 1235.43 & 536382 \\
\hline
\end{tabular}

TABLE 6: Effect of changing $B$ for different values of $\beta_{0}$ on the optimal policy.

\begin{tabular}{lcccccc}
\hline$B$ & \multicolumn{7}{c}{$\mathrm{TP}^{*}$} \\
$\beta_{0}=$ & 0.950 & 0.952 & 0.954 & 0.956 & 0.958 & 0.960 \\
245000 & 531706 & 524776 & - & - & - & - \\
250000 & 536293 & 535792 & 534568 & 532052 & 525886 & - \\
255000 & 536312 & 536138 & 535847 & 535430 & 534702 & 533153 \\
260000 & 536312 & 536138 & 535847 & 535430 & 534876 & 534172 \\
\hline
\end{tabular}

TABLE 7: The optimal results of the bifuzzy models.

\begin{tabular}{lcccc}
\hline Problem & $Q^{*}$ & $Q_{0}^{*}$ & $Q_{\text {total }}^{*}$ & TP $^{*}$ \\
\hline Model-5 & 397.55 & 850.91 & 1248.46 & 541570 \\
Model-6 & 396.16 & 852.95 & 1124.91 & 541568 \\
Model-7 & 392.29 & 828.38 & 1220.66 & 540840 \\
Model-8 & 255.20 & 902.60 & 1157.80 & 536394 \\
\hline
\end{tabular}

$f_{0}=0.88, c_{0}=1800, c=850, i=50, r=2000, s=1500$, $\beta_{0}=0.95$, and $B=2440000 ; X$ follows normal distribution with mean 800 and standard deviation 220; $Y$ follows uniform distribution over the interval $[40,90] ; \gamma_{0}=55, \gamma=70$.

Therefore $G_{1}=P(Y \geq \gamma)=0.40 ; G_{2}=P\left(\gamma_{0} \leq Y<\right.$ $\gamma)=0.30 ; G_{3}=P\left(Y<\gamma_{0}\right)=0.30$. The optimal results of the models are given in Table 1 .

7.1.1. Sensitivity Analysis. In this section, we perform sensitivity analysis by changing the values of some important parameters.

Model-1. The optimal solutions for different values of $\gamma$ are displayed in Table 2.

Figure 2 shows that as $\gamma$ increases, while all other parameters remain unchanged, the optimal ordered quantity of used product $Q^{*}$, total ordered quantity of raw material and used product $Q_{\text {total }}^{*}$, and the expected total profit $\mathrm{TP}^{*}$ have decreased but there is increase in optimal ordered quantity of raw material $Q_{0}^{*}$. This is an expected result because, for large value of the $\gamma$, the probability of nonconformance to used product of good quality increases so that manufacturer decides to order more raw material $\left(Q_{0}^{*}\right)$ at high cost than used product $\left(Q^{*}\right)$ resulting in a smaller value of profit $\left(\mathrm{TP}^{*}\right)$.

The behavior of $Q^{*}, Q_{0}^{*}, Q_{\text {total }}^{*}$, and $\mathrm{TP}^{*}$ with respect to $\gamma_{0}$ (see Figure 3 ) is found to be similar to that obtained with respect to $\gamma$; as $\gamma_{0}$ increases, $Q^{*}, Q_{\text {total }}^{*}$, and $\mathrm{TP}^{*}$ have decreased but there is increase in $Q_{0}^{*}$. Table 3 indicates that when $\gamma_{0}$ is increased above 52.5 then the ordered quantity of raw material $Q_{0}$ is greater than the ordered quantity of used product $Q$.

Model-2. Figure 4 presents how the ordering policy $Q^{*}, Q_{0}^{*}, Q_{\text {total }}^{*}$ and the expected total profit $\mathrm{TP}^{*}$ change as fill rate $\beta_{0}$ increases, while all other parameters remain same.

From Table 4 we find that for values of $\beta_{0}$ from $0 \%$ to $94 \%$ the optimal ordering policy $\left(Q^{*}, Q_{0}^{*}\right)$ and the total profit $\mathrm{TP}^{*}$ remain unchanged and their values are equal to the optimal values of unconstrained model. When the value of $\beta_{0}$ increases above $0.94, \mathrm{TP}^{* *}$ decreases rapidly and leads to a negative profit. It is observed that as $\beta_{0}$ increases the manufacturer, in order to meet market demand, increases the order quantity of raw material and decreases the order quantity of used product.

Model-3. Table 5 indicates that when $B$ lies in the interval ( 0 , 2500000), TP* increases as $B$ increases and the manufacturer produces more quantities of new product from the raw material and less from the used product to meet the demand. The marginal benefit of additional budget tends to zero as the budget amount increases above 2500000 and expected profit approaches the expected profit for unconstrained Model-1 (see Figure 5).

Model-4. In Table 6, we investigate the effect of the available budget amount $B$ for different values of $\beta_{0}$. The pattern of TP* versus $B$ plot in Figure 6 is similar to Figure 5.

7.2. Fuzzy Model. For fuzzy model we consider the same data as in crisp model, except the following bifuzzy numbers:

$$
\begin{aligned}
& \widetilde{\widetilde{\gamma}}(\theta)=(\gamma(\theta), 6,4)_{L R} \text { with } \gamma(\theta)=(70,3,2)_{L R}, \\
& \widetilde{\widetilde{\gamma}}_{0}(\theta)=\left(\gamma_{0}, 5,4\right)_{L R} \text { with } \gamma_{0}(\theta)=(55,2,1.5)_{L R}, \\
& \widetilde{\widetilde{\beta}}_{0}(\theta)=\left(\beta_{0}(\theta), 0.04,0.06\right)_{L R} \text { with } \beta_{0}(\theta)=(0.81,0.06 \text {, } \\
& 0.05)_{L R}, \\
& \widetilde{\widetilde{B}}(\theta)=(B(\theta), 200000,100000)_{L R} \text { with } B(\theta)= \\
& (2400000,300000,400000)_{L R},
\end{aligned}
$$

and we set $\delta=\zeta=\theta_{1}=\eta_{1}=\theta_{2}=\eta_{2}=0.95$. The optimal results of fuzzy models are given in Table 7 .

7.2.1. Sensitivity Analysis. In Table 8, we investigate the effect of changes in the predetermined levels $\delta, \zeta, \theta_{1}, \eta_{1}, \theta_{2}, \eta_{2}$ on $Q^{*}, Q_{0}^{*}, Q_{\text {total }}^{*}, \mathrm{TP}^{*}$ in the bifuzzy models. Table 8 indicates that Model-5 to Model-7 are significantly influenced by the predetermined levels, whereas Model- 8 is highly sensitive to the changes in predetermined levels.

\section{Conclusion}

In this paper, we have studied a closed-loop supply chain model where manufacturer satisfies stochastic market demand by remanufacturing/recycling used product and manufacturing new product. We assume that the quality of the used product is random and remanufacturing cost 
TABLE 8: Effect of predetermined level on the optimal policy.

\begin{tabular}{|c|c|c|c|c|c|}
\hline$\left(\delta, \zeta, \theta_{1}, \eta_{1}, \theta_{2}, \eta_{2}\right)$ & Problem & $Q^{*}$ & $\begin{array}{c}\% \text { change in } \\
Q_{0}^{*}\end{array}$ & $Q_{\text {total }}^{*}$ & $\mathrm{TP}^{*}$ \\
\hline \multirow{4}{*}{$(0.93,0.93,0.93,0.93,0.93,0.93)$} & Model-5 & 3.2993 & -0.9157 & 0.4265 & 0.4079 \\
\hline & Model-6 & 3.1311 & -0.7988 & 0.4476 & 0.4073 \\
\hline & Model-7 & 3.5737 & -0.3689 & 0.8981 & 0.4600 \\
\hline & Model-8 & 19.3072 & -2.4600 & 2.3379 & 0.8497 \\
\hline \multirow{4}{*}{$(0.95,0.95,0.93,0.93,0.93,0.93)$} & Model-5 & 0.0000 & 0.0000 & 0.0000 & 0.0000 \\
\hline & Model-6 & 0.3502 & -0.2386 & -0.0518 & 0.0005 \\
\hline & Model-7 & 0.1800 & 0.5002 & 0.3973 & 0.0442 \\
\hline & Model-8 & 19.3065 & -2.4598 & 2.3378 & 0.5345 \\
\hline \multirow{4}{*}{$(0.95,0.95,0.97,0.97,0.97,0.97)$} & Model-5 & 0.0000 & 0.0000 & 0.0000 & 0.0000 \\
\hline & Model-6 & -0.7014 & 0.4743 & 0.1014 & -0.0036 \\
\hline & Model-7 & -0.1544 & -0.5067 & -0.3935 & -0.0532 \\
\hline & Model-8 & -27.6676 & 3.7477 & -3.1768 & -1.1617 \\
\hline \multirow{4}{*}{$(0.97,0.97,0.97,0.97,0.97,0.97)$} & Model-5 & -3.2323 & 0.8923 & -0.4211 & -0.3936 \\
\hline & Model-6 & -3.1029 & 0.7975 & -0.4736 & -0.3933 \\
\hline & Model-7 & -3.4820 & 0.3474 & -0.8832 & -0.4584 \\
\hline & Model-8 & -27.6697 & 3.7480 & -3.1770 & -1.3526 \\
\hline
\end{tabular}

depends on the quality of used product. We first derive the proposed base case unconstrained model in Model-1. Following that we investigate the model in the presence of fill rate constraint and budget constraint (Model-2 to -4). Next to overcome uncertainty in some parameters, we develop the models in bifuzzy environment (Model5 to -8$)$. We perform a comparison of optimal results of the models through numerical examples. Analysis result shows that in low-budget scale industry manufacturer produces more quantities of new product from the used product and less from the raw material to meet the demand but in order to prevent shortage the manufacturer adopts manufacturing policy rather than remanufacturing policy.

This paper is limited in the sense that (i) brand-new products and as-new products are absolutely substituted by each other and sold at the same price; (ii) the return rate of used product is infinite. This limitation suggests an interesting extension to our research work.

\section{Notations}

$X: \quad$ A random variable denoting the market demand

$f(\cdot)$ : Probability density function of the market demand

$F(\cdot)$ : Cumulative density function of the market demand

$Y$ : A random variable denoting the quality characteristic of used item

$g(\cdot)$ : Probability density function of the quality characteristic of used item

$\gamma$ : The good quality level (GQL) of the used product $\gamma_{0}: \quad$ The rejected quality level (RQL) of the used product

$G_{1}$ : the probability that the quality of collected lot of used items satisfies GQL;

$G_{1}=P(Y \geq \gamma)$

$G_{2}$ : The probability that the quality of collected lot of the used items is below GQL but above RQL; $G_{1}=P\left(\gamma_{0} \leq Y \leq \gamma\right)$

$G_{3}$ : The probability that quality of collected lot of the used items is below RQL; $G_{3}=P\left(Y<\gamma_{0}\right)$

$Q: \quad$ Collected quantity of used product

$Q_{0}$ : Ordered quantity of raw material

$Q_{\text {total }}$ : Total ordered quantity of raw material and used product

p: $\quad$ Unit selling price of product

$c$ : Unit purchasing cost of used product

$c_{0}$ : Unit purchasing cost of raw material, where $c_{0}>c$

$i$ : Unit inspection cost of used product

$p_{0}$ : Unit manufacturing cost of raw material

$p_{1}$ : Unit remanufacturing cost of used item, the quality of which satisfies GQL

$p_{2}$ : Unit remanufacturing cost of used item, the quality of which is below GQL but above RQL, where $p_{1} \leq p_{2}$

$f_{0}$ : Conversion factor of raw material to finished new product

$f_{1}$ : Conversion factor of used item (the quality of which satisfies GQL) to finished new product

$f_{2}$ : Conversion factor of used item (the quality of which is below GQL but above RQL) to finished new product, where $f_{1} \geq f_{2}$

$r$ : $\quad$ Unit salvage cost, where $r>p$

$s$ : Unit shortage cost. 


\section{Conflict of Interests}

The authors declare that there is no conflict of interests regarding the publication of this paper.

\section{References}

[1] E. van der Laan, M. Salomon, R. Dekker, and L. van Wassenhove, "Inventory control in hybrid systems with remanufacturing," Management Science, vol. 45, no. 5, pp. 733-747, 1999.

[2] H. Krikke, "Impact of closed-loop network configurations on carbon footprints: a case study in copiers," Resources, Conservation and Recycling, vol. 55, no. 12, pp. 1196-1205, 2011.

[3] K. Inderfurth, "Optimal policies in hybrid manufacturing/ remanufacturing systems with product substitution," International Journal of Production Economics, vol. 90, no. 3, pp. 325343, 2004.

[4] I. Dobos and K. Richter, "An extended production/recycling model with stationary demand andreturn rates," International Journal of Production Economics, vol. 90, pp. 311-323, 2004.

[5] D.-W. Choi, H. Hwang, and S.-G. Koh, "A generalized ordering and recovery policy for reusable items," European Journal of Operational Research, vol. 182, no. 2, pp. 764-774, 2007.

[6] S. Rubio and A. Corominas, "Optimal manufacturingremanufacturing policies in a lean production environment," Computers and Industrial Engineering, vol. 55, no. 1, pp. 234-242, 2008.

[7] C. A. Yano and L. H. Lee, "Lot sizing with random yields: a review," Operations Research, vol. 43, no. 2, pp. 311-334, 1995.

[8] A. Hsu and Y. Bassok, "Random yield and random demand in a production system with downward substitution," Operations Research, vol. 47, no. 2, pp. 277-290, 1999.

[9] S. Bollapragada and T. E. Morton, "Myopic heuristics for the random yield problem," Operations Research, vol. 47, no. 5, pp. 713-722, 1999.

[10] B. Kazaz, "Production planning under yield and demand uncertainty with yield-dependent cost and price," Manufacturing and Service Operations Management, vol. 6, no. 3, pp. 209-224, 2004.

[11] N. Steven, "Inventory control subject to uncertain demand," in Production and Operations Analysis, pp. 255-261, McGraw-Hill Irwin, New York, NY, USA, 5th edition, 2005.

[12] P. H. Zipkin, Foundations of Inventory Management, McGrawHill, New York, NY, USA, 2000.

[13] S. Axsäter, "A simple procedure for determining order quantities under a fill rate constraint and normally distributed leadtime demand," European Journal of Operational Research, vol. 174, no. 1, pp. 480-491, 2006.

[14] L. A. Zadeh, "Fuzzy sets," Information and Computation, vol. 8, no. 3, pp. 338-353, 1965.

[15] D. K. Jana, B. Das, and T. K. Roy, "A partial backlogging inventory model for deteriorating item under fuzzy inflation and discounting over random planning horizon: a fuzzy genetic algorithm approach," Advances in Operations Research, vol. 2013, Article ID 973125, 13 pages, 2013.

[16] D. K. Jana, K. Maity, B. Das, and T. K. Roy, "A fuzzy simulation via contractive mapping genetic algorithm approach to an imprecise production inventory model under volume flexibility," Journal of Simulation, vol. 7, no. 2, pp. 90-100, 2013.

[17] D. K. Jana, B. Das, and M. Maiti, "Multi-item partial backlogging inventory models over random planning horizon in
Random Fuzzy environment," Applied Soft Computing, vol. 21, pp. 12-27, 2014.

[18] L. A. Zadeh, "The concept of a linguistic variable and its application to approximate reasoning. I," Information Sciences, vol. 8, no. 3, pp. 199-249, 1975.

[19] L. A. Zadeh, "The concept of a linguistic variable and its application to approximate reasoning-II," Information Sciences, vol. 8, no. 4, pp. 301-357, 1975.

[20] L. A. Zadeh, "The concept of a linguistic variable and its application to approximate reasoning-III," Information Sciences, vol. 9, no. 1, pp. 43-80, 1975.

[21] J. M. Mendel, John, and R.I. B, “Type-2 fuzzy sets made simple," IEEE Transactions on Fuzzy Systems, vol. 10, no. 2, pp. 117-127, 2002.

[22] L. A. Zadeh, "Quantitative fuzzy semantics," Information Sciences, vol. 3, no. 2, pp. 159-176, 1971.

[23] S. Gottwald, "Set theory for fuzzy sets of higher level," Fuzzy Sets and Systems, vol. 2, no. 2, pp. 125-151, 1979.

[24] J. Xu and X. Zhou, Fuzzy Link Multiple-Objective Decision Making, Springer, Berlin, Germany, 2009.

[25] S. Pramanik, D. K. Jana, and M. Maiti, "Multi-objective solid transportation problem in imprecise environments," Journal of Transportation Security, vol. 6, no. 2, pp. 131-150, 2013.

[26] B. Liu, Theory and Practice of Uncertain Programming, Physica, Heidelberg, Germany, 2002. 


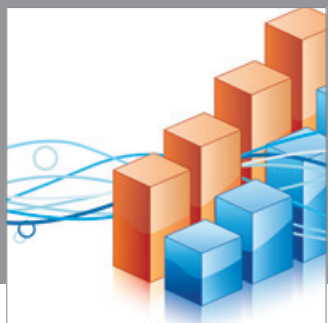

Advances in

Operations Research

mansans

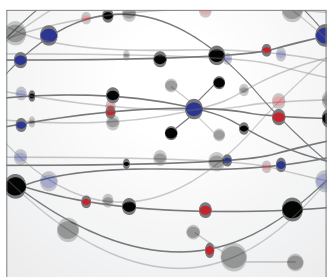

The Scientific World Journal
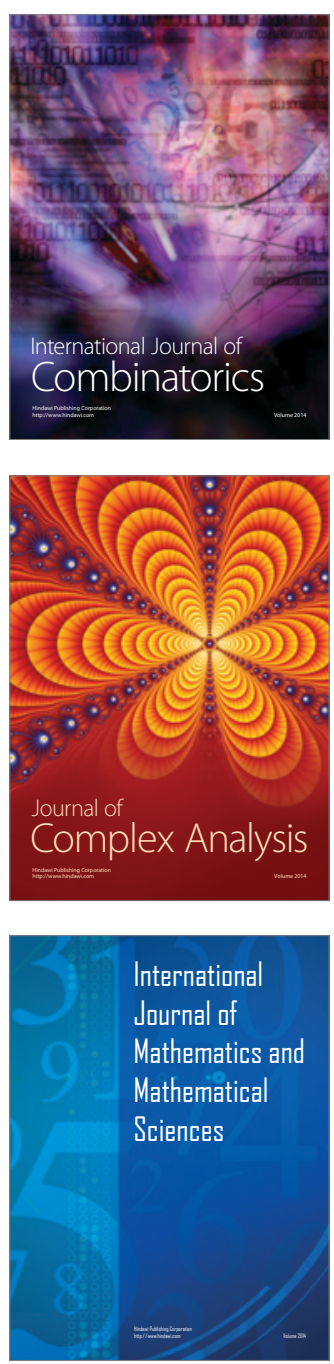
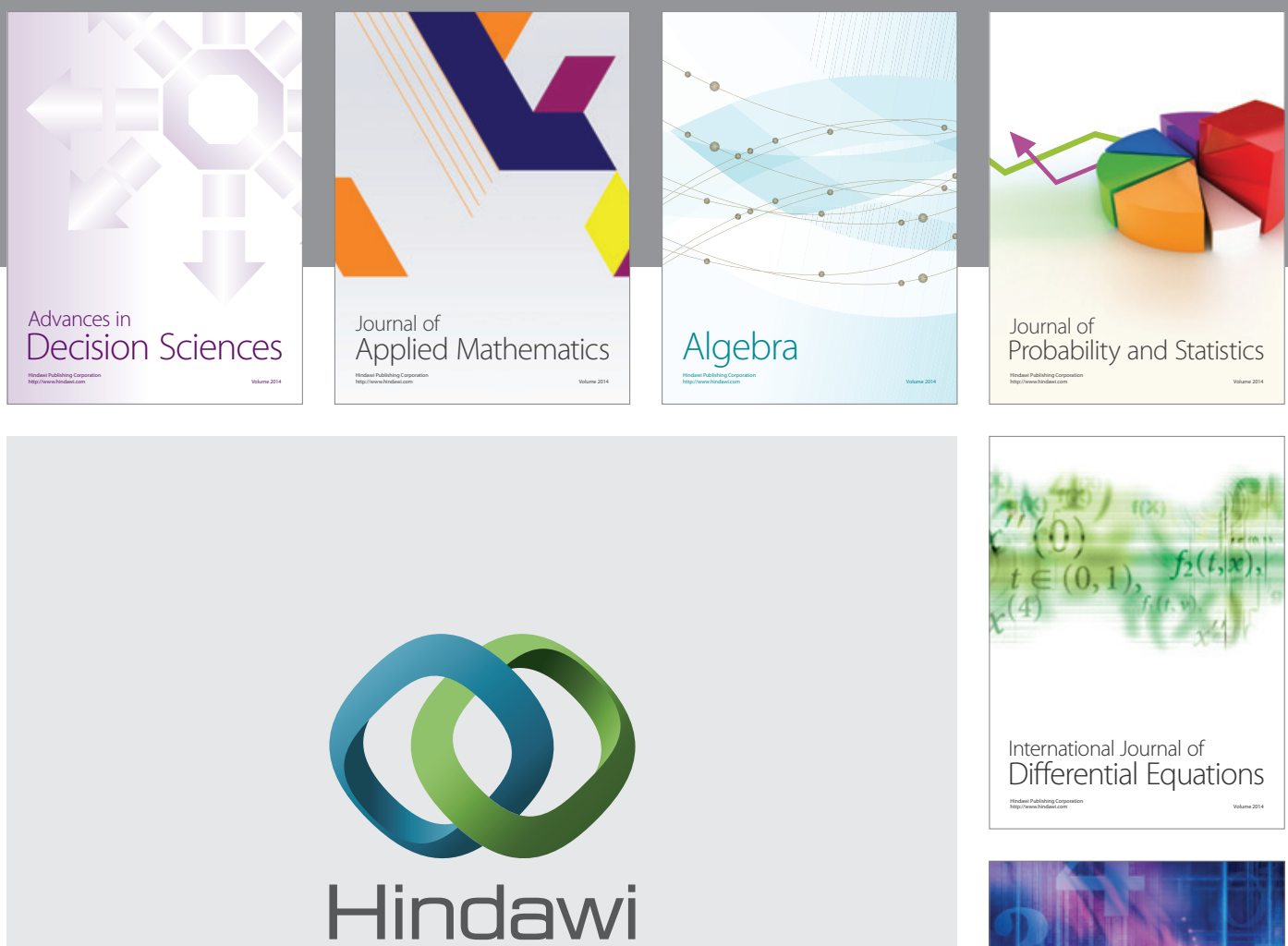

Submit your manuscripts at http://www.hindawi.com
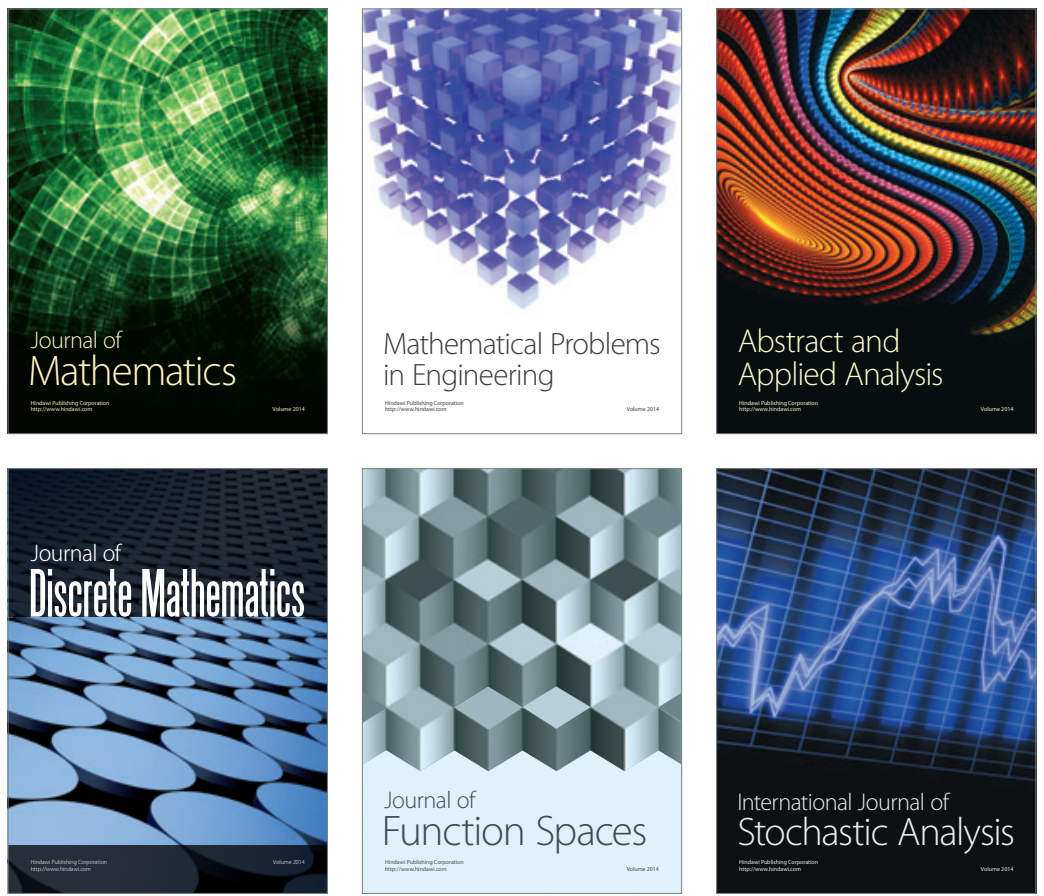

Journal of

Function Spaces

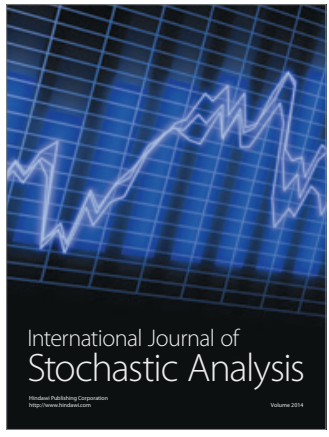

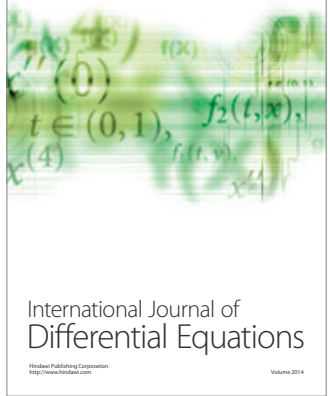
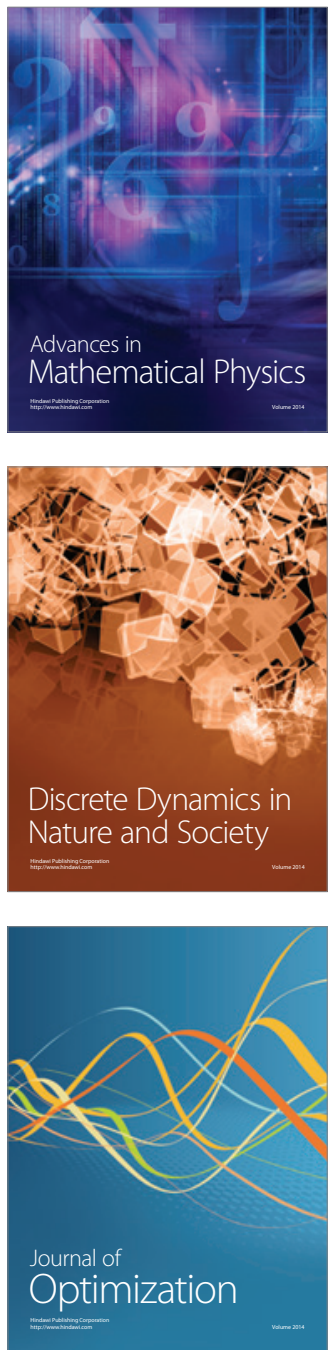